\title{
The Heterogeneous Coagulation and Flocculation of Brewery Wastewater Using
}

\section{Carbon Nanotubes}

\author{
Geoffrey S. Simate $^{\mathrm{a},{ }^{*}}$, Sunny E. Iyuke ${ }^{\mathrm{a}}$, Sehliselo Ndlovu ${ }^{\mathrm{a}}$, Mike Heydenrych ${ }^{\mathrm{b}}$
}

\footnotetext{
${ }^{a}$ School of Chemical and Metallurgical Engineering, University of the Witwatersrand, Johannesburg, P/Bag 3, Wits 2050, South Africa

${ }^{b}$ Department of Chemical Engineering, University of Pretoria, P/Bag X20, Hatfield 0028, South Africa

* Corresponding author. Tel: +27 11717 7570; Cell: +27 76112 6959; Fax: +27 117177599

Email: simateg@yahoo.com (G.S.Simate)
}

\section{Highlights}

Different chemicals were compared for the coagulation and flocculation of brewery wastewater.

$>$ Carbon nanotubes can be used as heterogeneous coagulants in the pretreatment of brewery wastewater.

Ferric chloride was a more effective coagulant than both functionalised and pristine CNTs.

\begin{abstract}
Coagulation and flocculation treatment processes play a central role in the way wastewater effluents are managed. Their primary function is particle removal that can impart color to a water source, create turbidity, and/or retain bacterial and viral organisms. This study was carried out to investigate whether carbon nanotubes (CNTs) can be used as heterogeneous coagulants and /or flocculants in the pretreatment of brewery wastewater. A series of experiments were conducted in which the efficiencies of pristine and functionalised CNTs were compared with the efficiency of traditional ferric chloride in a coagulation/flocculation process. Turbidity and chemical oxygen demand (COD), including the zeta potential were used to monitor the progress of the


coagulation/flocculation process. Both pristine and functionalised CNTs demonstrated the ability to successfully coagulate colloidal particles in the brewery wastewater. Overall, ferric chloride was found to be a more effective coagulant than both the pristine and functionalised CNTs.

Keywords: brewery wastewater treatment; carbon nanotubes; heterogeneous coagulation and flocculation; turbidity; chemical oxygen demand; zeta potential

\section{Graphical abstract}

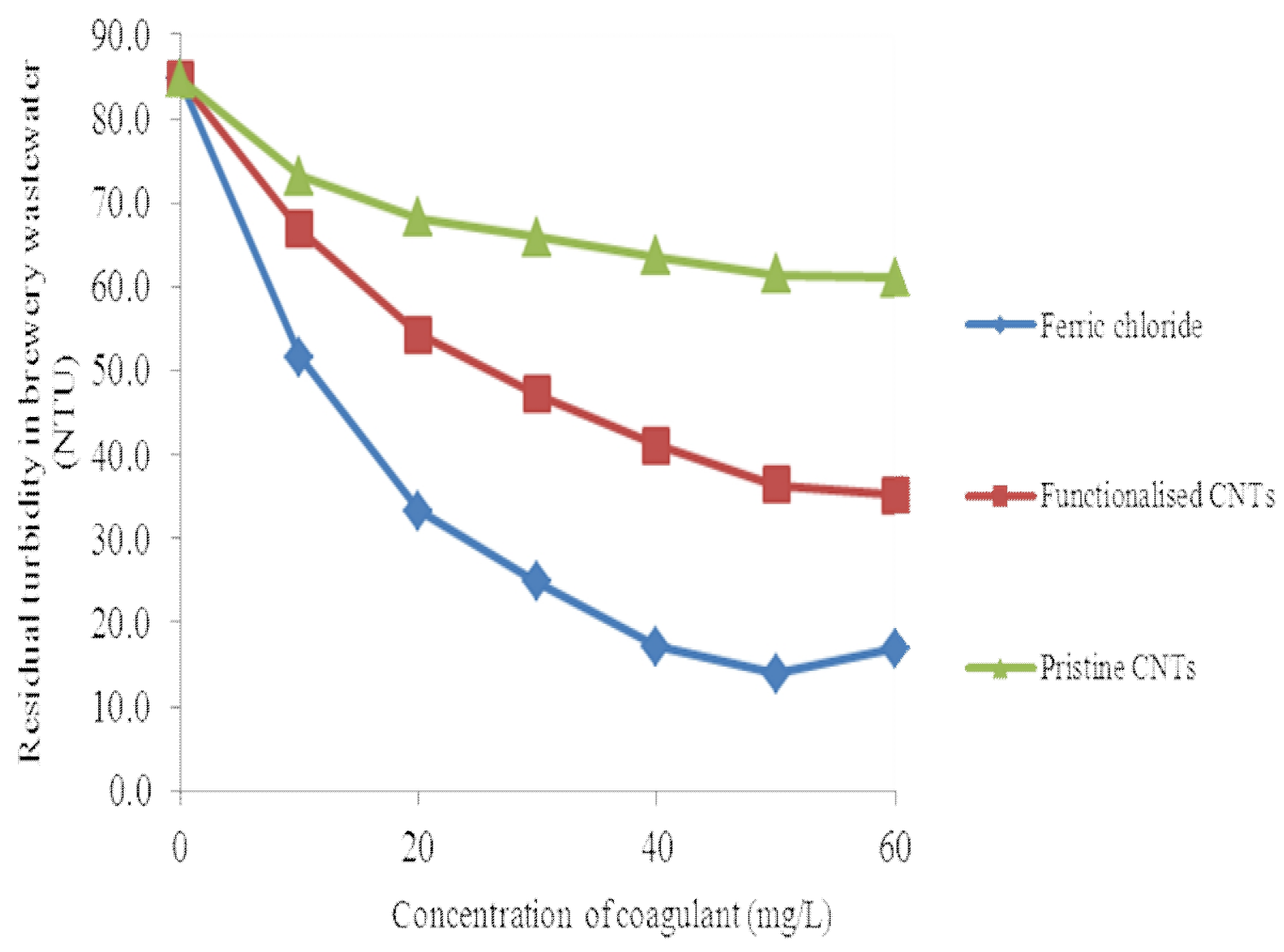

\section{Introduction}

The brewery industry is one of the industries which use large quantities of water, and generate enormous amounts of wastewater. The wastewater from these industries contains large quantities of toxic chemicals which may pose serious risk to human beings, the environment, and aquatic life if 
not properly treated prior to consumption or disposal. As a result, the treatment and safe disposal of brewery wastewaters has become an important aspect in the running of breweries. A good number of brewery wastewater treatment methods are either in operation, being piloted or under evaluation (Simate et al., 2011). These treatment processes are selective depending on various factors including the following: the purpose of water and its quality requirements (Seo et al., 1996), wastewater characteristics (Chuang et al., 2005), etc.

Based on theory and practical experience, membrane technologies have always been the core wastewater treatment processes for removal of dissolved species (Sadr et al., 1998; Madwar and Tarazi, 2002; Sahachaiyunta et al., 2002). When considering the pretreatment units required for protecting the membrane systems, activated carbon adsorption is employed intensively for organic component removal (Tsujimoto et al., 1998; Weber and LeBoeuf, 1999; Abdessemed et al., 2000); microfiltration and dissolved air flotation are used for solid and colloid removal (Bernard et al., 1995; Zouboulis and Matis, 1995; Féris and Rubio, 1999). In addition, ion exchange columns could be designed to eliminate the ionic matter so as to improve the quality of the effluent (Rengaraj et al., 2001).

However, over the years, coagulation and flocculation have remained the widely used methods for water and wastewater pretreatment. These physicochemical processes are commonly used for the removal of colloidal material, which cause colour and turbidity (Amuda and Alade, 2006). Often, the terms coagulation and flocculation are used synonymously despite an existing subtle difference between the two (Tripathy and Ranjan De, 2006). In water and wastewater treatment, coagulation implies the step where particles are destabilised by a coagulant, and this may include the formation of small aggregates by the Brownian motion (perikinetic coagulation). On the other hand, the subsequent process in which larger aggregates (flocs) are formed by the action of shear is known as flocculation (Gregory, 2006). After small particles have formed larger aggregates, colloidal material 
can then be more easily removed by physical separation processes such as sedimentation, flotation, and filtration (Simate et al., 2011).

At present, compounds such as alum, ferric chloride, and polymers have been used extensively in the coagulation and flocculation processes. However, the current traditional coagulants and flocculants have several disadvantages. The chemicals used result in a net increase in the dissolved constituents associated with the added metal coagulants in the final wastewater (Barrera-Díaz et al., 2009). With aluminum salts, the residual in the treated water causes Alzheimer's disease (Simate et al., 2012), and a very large volume of sludge is generated (Liew et al., 2006). Iron based coagulants have lower $\mathrm{pH}$ and are much more corrosive due to the lower $\mathrm{pK}_{\mathrm{a}}$ values for $\mathrm{Fe}^{3+}$, oxidising power, and the catalytic effect of chloride at the low pH of ferric coagulants (Newcombe and Dixon, 2006). Since high concentrations of traditional coagulants/flocculants in water may have severe adverse implications including human health effects, environmentally friendly coagulants will present an interesting alternative for the treatment and purification of wastewaters.

Fortunately, the advent of nanotechnology has brought a lot of hope, and that nanotechnology for water purification has been identified as a high priority area for most research institutions and national governments. Amongst the nanomaterials that are used in the water treatment, carbon nanotubes (CNTs) have been the focus of considerable study because of their adsorption properties. They have shown exceptional adsorption capabilities and high adsorption efficiencies for various organic pollutants (Lu et al., 2005; Goering and Burghaus, 2007; Lu and Su, 2007; Li et al., 2007) and inorganic pollutants such as fluoride (Li et al., 2003a). The CNTs have also been found to be superior sorbents for heavy metals (Li et al., 2003b; Li et al., 2006; Li et al., 2007). The CNTs are particularly attractive as sorbents because, on the basis of mass, they have larger surface areas than bulk particles, and that can be functionalised with various chemical groups to increase their affinity 
towards target compounds (Savage and Diallo, 2005). The CNTs also have small size, and are hollow with layered structures ( $\mathrm{Wu}, 2007)$, which are important attributes for adsorption.

In literature CNTs have been proven to possess good potential as superior adsorbents for removing many kinds of organic and inorganic pollutants, and heavy metals from aqueous solutions, to the best of the authors' knowledge, no published work is available regarding their application as heterogeneous coagulants and/or flocculants. Furthermore, despite the brewery industry being a large consumer of groundwater in most countries, the use of CNTs for brewery wastewater treatment has not been explored. However, it can be theorised that if CNTs can adsorb on separate colloidal particles, then the particles can be drawn together; a phenomenon known as bridging flocculation (Simate et al., 2011). Furthermore, the adsorption of CNTs onto particle surfaces can also result in charge neutralisation (Simate et al., 2011). Once the surface charge has been neutralised, the ionic cloud dissipates and the electrostatic potential disappears resulting in a near zero net charge so that the contact among colloidal particles occurs freely. The control of surface charges or, in other words, the control of zeta potential of the CNTs is needed to effect adsorption. These are the conceptual (fundamental) theories upon which this study is based. The purpose of this study is, therefore, to evaluate the potential application and performance of CNTs as heterogeneous coagulants and/or flocculants.

\section{Materials and Methods}

\subsection{Samples and preparation}

The brewery waste water used in this study was provided by the South African Breweries Ltd. It was obtained from the outlet of the up-flow anaerobic sludge blanket (UASB) reactor in plastic containers. The collected wastewater was allowed to settle for 24 hours, and the supernatant was 
carefully collected and stored at $4{ }^{\circ} \mathrm{C}$ for use in subsequent test works. The water quality parameters for both the raw and treated brewery wastewater were measured as indicated in the American Public Health Association (APHA) standard procedures (Clesceri et al. 1998). Water quality characteristics of the wastewater in this study are summarised in Table1.

To compare the coagulation/flocculation capability of CNTs, ferric chloride obtained from Merck (South Africa) was used. Ferric chloride was chosen amongst other inorganic coagulants such as alum because it is effective over a wider $\mathrm{pH}$ range of 4-11, and that the ferric hydroxide floc is heavier than alum, thus improving its settling characteristics (Ebeling et al., 2003). Because there was enough alkalinity in the brewery wastewater (see Table 1), no alkalinity additions were required with ferric chloride treatments.

Table 1 - Water quality characteristics of the brewery wastewater.

\begin{tabular}{lccc}
\hline Parameter & Mean & Standard Deviation & Range \\
\hline $\mathrm{pH}$ & 8.3 & 0.2 & $7.9-8.7$ \\
Alkalinity $\left(\mathrm{mg} \mathrm{CaCO}_{3} / \mathrm{L}\right)$ & 21.8 & 3 & $19.7-25.2$ \\
Turbidity $(\mathrm{NTU})$ & 85 & 6 & $79-94$ \\
$\mathrm{COD}(\mathrm{mg} / \mathrm{L})$ & 597.3 & 50 & $454-673$ \\
Conductivity $(\mathrm{mS} / \mathrm{cm})$ & 3.12 & 0.12 & $2.44-4.71$ \\
Zeta potential $(\mathrm{mV})$ & -38 & 0.8 & $-53-(-19)$ \\
\hline
\end{tabular}

The CNTs used in this study were produced from carbon dioxide by the chemical vapour deposition (CVD) method as described elsewhere (Simate et al., 2010; Xu and Huang, 2007; Iyuke and Simate, 2011). The crude pristine CNTs produced were purified by treating them with $10 \%$ nitric acid by gentle vortexing for $2 \frac{1}{2}$ hours at $120^{\circ} \mathrm{C}$ (Yah et al., 2011). The lower acid concentration was to remove the impurities, but prevent the CNTs from being oxidised. The products were filtered, washed repeatedly with deionised water until a $\mathrm{pH}$ of 7 was reached, and were dried at $80^{\circ} \mathrm{C}$ in a hot air oven overnight (Yah et al., 2011). After purification, it is important to modify the surfaces of CNTs so that they develop affinity for the removal of colloidal particles from the brewery 
wastewater. It is an established fact that CNT surfaces can display acidic, basic and/or neutral characteristics depending on the presence of surface functional groups (Naseh et al., 2009; MontesMoran et al., 2004; Xu et al., 2007; González-Guerrero et al., 2008). In addition, the amount and type of oxygen-containing functional groups depends on the treatment methods (Naseh et al., 2009). In this study, basic CNTs would be suitable for heterogeneous coagulation of the colloidal particles in the brewery wastewater. Therefore, the functionalisation of CNTs was carried out using hydrochloric acid. It has been widely shown that hydrochloric acid is an effective reagent for functionalising CNTs (Cortes et al., 2010). In addition, hydrochloric acid has been found to be effective in changing the zeta potential of carbon material in the positive direction (Suzuki and Chihara, 1988). The CNTs were functionalised by soaking $100 \mathrm{~g}$ of purified CNTs in concentrated hydrochloric acid overnight, and then filtered. The filtered CNTs were rinsed with deionised water until the $\mathrm{pH}$ of 7 was reached.

\subsection{Characterisation tests}

Transmission electron microscopy (TEM, JEOL JEM-4010) was used to depict the morphological pattern of the CNTs including tube dimensions and level of aggregation. Raman spectroscopy (Renishaw micro-Raman 2000) using the standard $514.5 \mathrm{~nm}$ line of an argon ion laser was used to provide the structural characteristics of the CNTs and an indication of the degree of crystallinity. The scanning electron microscopy (SEM, Hitachi S-4300) was used to generate micrographs for comparing the surface morphologies of CNTs after the coagulation/flocculation process. The carbon content of the CNTs and their thermal stability were determined by a thermogravimetric analyser (TGA, TG 209 F1 Libra). In the TGA experiments, the sample was heated in air from about 30 to $750^{\circ} \mathrm{C}$ at a rate of $10^{\circ} \mathrm{C} / \mathrm{min}$. The specific surface areas of the $\mathrm{CNTs}$ were measured by nitrogen adsorption/desorption at $77 \mathrm{~K}$ using BET analyser. 
Functional groups on the surface of the CNTs were identified using Fourier transform infrared (FTIR) spectrometer. The Boehm's titration method (Boehm, 1966; Boehm, 1994) was used to quantitatively determine the concentrations of the basic and acidic functional groups on the surfaces of CNT. The Zetasizer (Malvern Instruments Zetasizer Nano series Nano ZS) was used to measure the zeta potential. The $\mathrm{pH}$ of the point of zero charge (pzc) or isoelectric point (IEP) was determined using the procedure of mass titration (Noh and Schwarz, 1988; Noh and Schwarz, 1990). This method was chosen because of its accuracy, and that the widely used acid/base titration method has limited success for carbons (Noh and Schwarz, 1990).

\subsection{Coagulation and flocculation tests}

Initially, a stock suspension of $1000 \mathrm{mg} / \mathrm{L}$ of CNTs was prepared by adding $100 \mathrm{mg}$ of CNTs to $100-\mathrm{mL}$ of distilled water and mixed over a magnetic stirrer at $500 \mathrm{rpm}$. The stock suspension was continuously mixed during the duration of the experiments. A stock solution of ferric chloride was also prepared. Jar tests were then carried out to evaluate the coagulation activity of CNTs and ferric chloride. Six equal volume polyethylene beakers were used to examine the different dosages of coagulant or initial $\mathrm{pH}$ values in each run. In a typical experiment, exactly $100-\mathrm{mL}$ of brewery waste water was measured into each jar test beaker. The $\mathrm{pH}$ was adjusted accordingly using $0.1 \mathrm{~N}$ $\mathrm{HCl}$ or $0.1 \mathrm{~N} \mathrm{NaOH}$ before addition of the coagulant. The stirrer speed was set to the predetermined 'flash mix' value of $150 \mathrm{rpm}$, and the brewery wastewater was then spiked with small volumes of stock suspension or stock solution of either CNTs or ferric chloride, respectively, near the vortex to achieve predetermined concentrations of CNTs or ferric chloride. After the predetermined 'flash mix' duration of 3 minutes, the mixing speed was reduced to the predetermined flocculation or 'slow mix' of $60 \mathrm{rpm}$ for a specified period of 20 minutes. After this time period, the stirrer was withdrawn and the floc was allowed to settle for a specified time of 30 minutes. However, since no flocs were visible due to poor dispersivity of CNTs, the treated water was filtered through a 
Whatman \# 1 equivalent paper and the parameters of the filtered water measured as an indication of coagulation (Nozaic et al., 2001). The parameters analysed were turbidity and chemical oxygen demand (COD).

\section{$3 \quad$ Results and Discussion}

\subsection{Characterisations of CNTs}

The TEM technique is a powerful tool for analysing the morphological make up of the CNTs. This technique provides an important characterization tool for carbon-based materials, showing different characteristic spectra for $\mathrm{sp}^{3}, \mathrm{sp}^{2}$, and $\mathrm{sp}$ carbons, as well as for disordered $\mathrm{sp}^{2}$ carbons, fullerenes, and CNTs (Osorio et al., 2008). It also helps to qualitatively analyse the quality (or purity) of the CNTs. The TEM photos in Figure 1 show hollow structures with inner diameter and length of several nanometers which confirm the presence of CNTs. It can be seen in Figure 1 that there are no loosely bound clusters, meaning that both the as-produced (pristine) and purified CNTs are free of amorphous carbon.
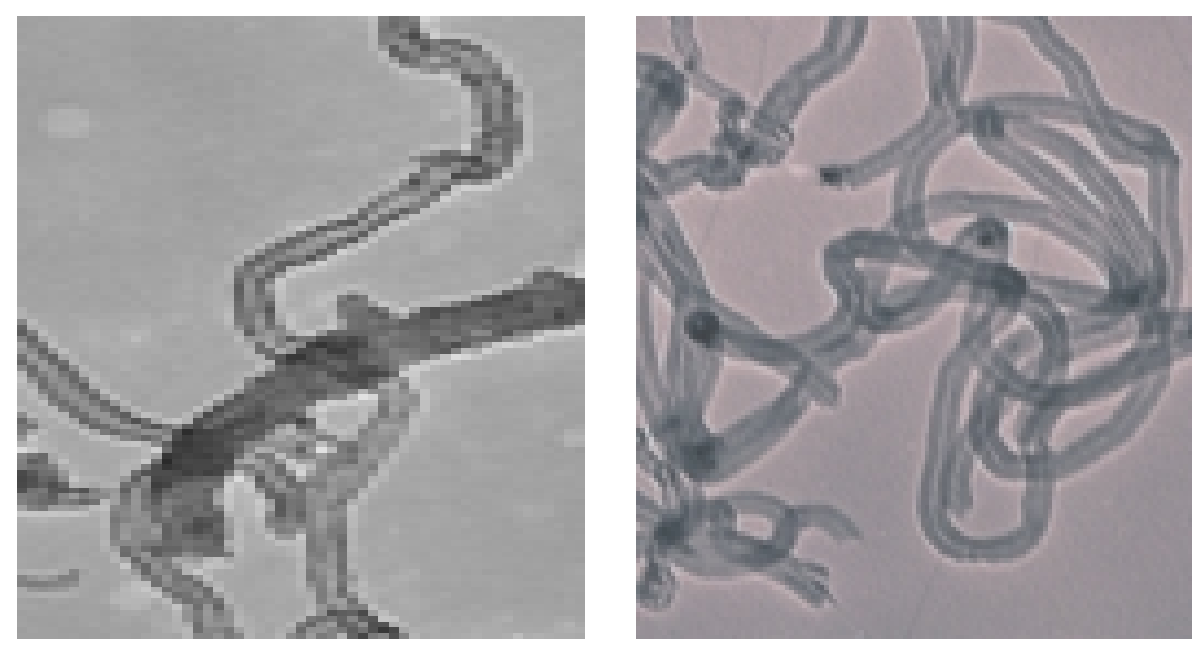

Fig. 1 - TEM image of (a) pristine CNTs and (b) acid treated CNTs

The TGA analysis carried out on pristine and purified CNTs in oxygen atmosphere to monitor the weight loss and thermal stability of the CNTs is shown in Figure 2. It is evident that both CNTs are 
considerably stable and show a little weight loss below $500^{\circ} \mathrm{C}$. From this figure, it is found that the initial burning temperature was at around $580^{\circ} \mathrm{C}$ and this occurred mainly due to the presence of amorphous carbon in the CNTs mixture (Ramesh et al., 2006). This is in contrast to Figure 1 which shows no significant evidence of amorphous carbon. Figure 2 also shows that gasification of both samples ends at about $600^{\circ} \mathrm{C}$ at which $2.81 \%$ and $1.22 \%$ remaining weight was observed for pristine and acid treated CNTs, respectively. This shows that the purity or carbon content of CNTs increases slightly from $97.19 \%$ to $98.78 \%$ after acid treatment. However, the following should be noted when using the TGA data. The information from TGA is primarily derived from the change in weight, which then is indirectly related to reactivity or oxidation (Brukh and Mitra, 2007). Since it does not distinguished between the reactants and the products, it can be affected by factors other than true amorphous carbon (Brukh and Mitra, 2007). For example, the weight of the residual catalyst, its oxidation, and the adsorption/desorption of other species can bias the results. Consequently, the oxidation of amorphous carbon should really be studied based on product formation, rather than weight loss. However, the study in this paper is beyond the scope of such studies.

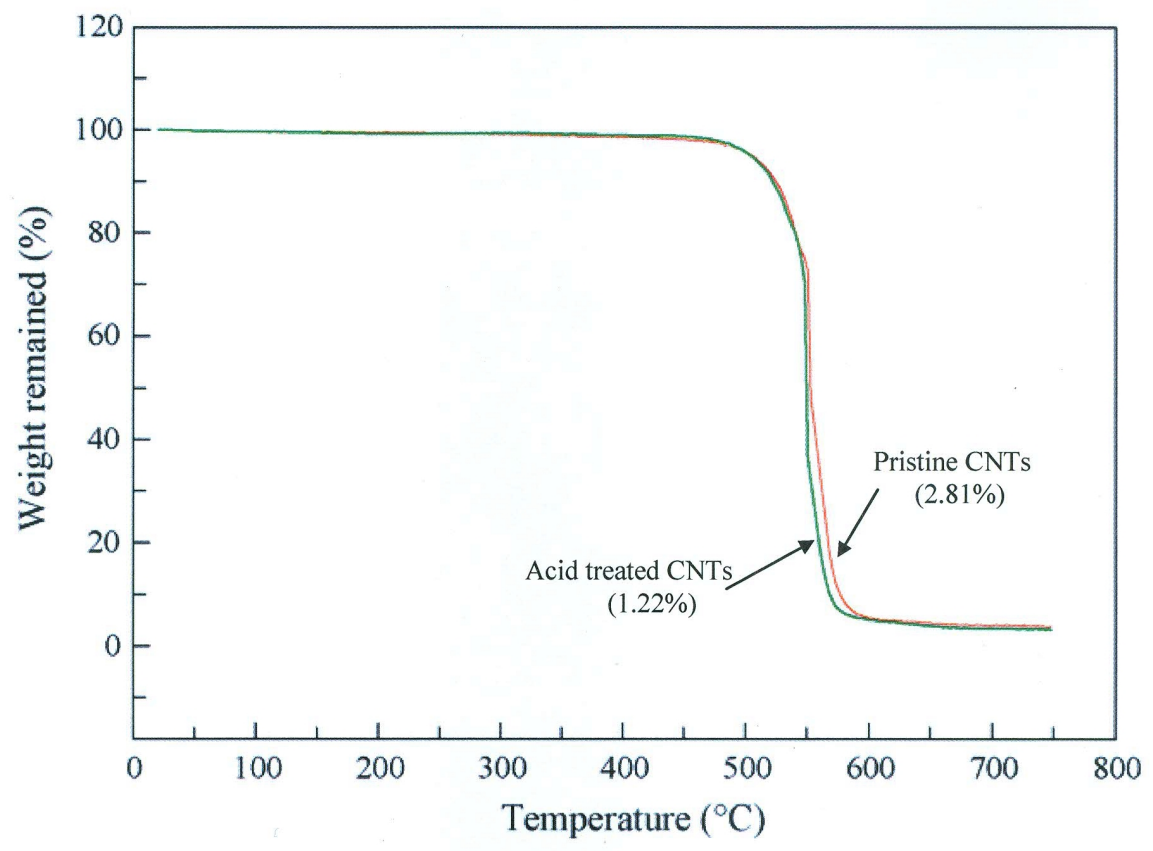

Fig. 2 - TGA of pristine and purified CNTs in oxygen atmosphere 
The Raman spectra of both the pristine and acid functionalised CNTs excited with the 514.5 $\mathrm{nm}$ laser line are shown in Figure 3. Raman spectroscopy is a useful technique for characterizing CNTs because it reveals information related to tube diameter and the degree of structural perfection of the graphene sheets (Dresselhaus and Eklund, 2000; Saito et al., 2000). The basis of most studies involving the Raman spectra evolve around the assignment of the G-band (graphitic, $\sim 1580 \mathrm{~cm}^{-1}$ ) to crystalline graphite and any other bands, called D-bands (disorder, various from 1100 to 1500 $\mathrm{cm}^{-1}$ ) to any type of structural disorder in the graphitic structure (Potgieter-Vermaak et al., 2011). As can be seen from the Raman spectra, the two characteristic peaks of CNTs, named the D band at $1358 \mathrm{~cm}^{-1}$ and the $\mathrm{G}$ band at $1582 \mathrm{~cm}^{-1}$, approximately, are easily identified. When oxidation (or functionalisation) of nanotubes was performed, these characteristic peaks can still be identified, proving that the acid treatment did not damage the structure of the CNTs. The Raman intensity of

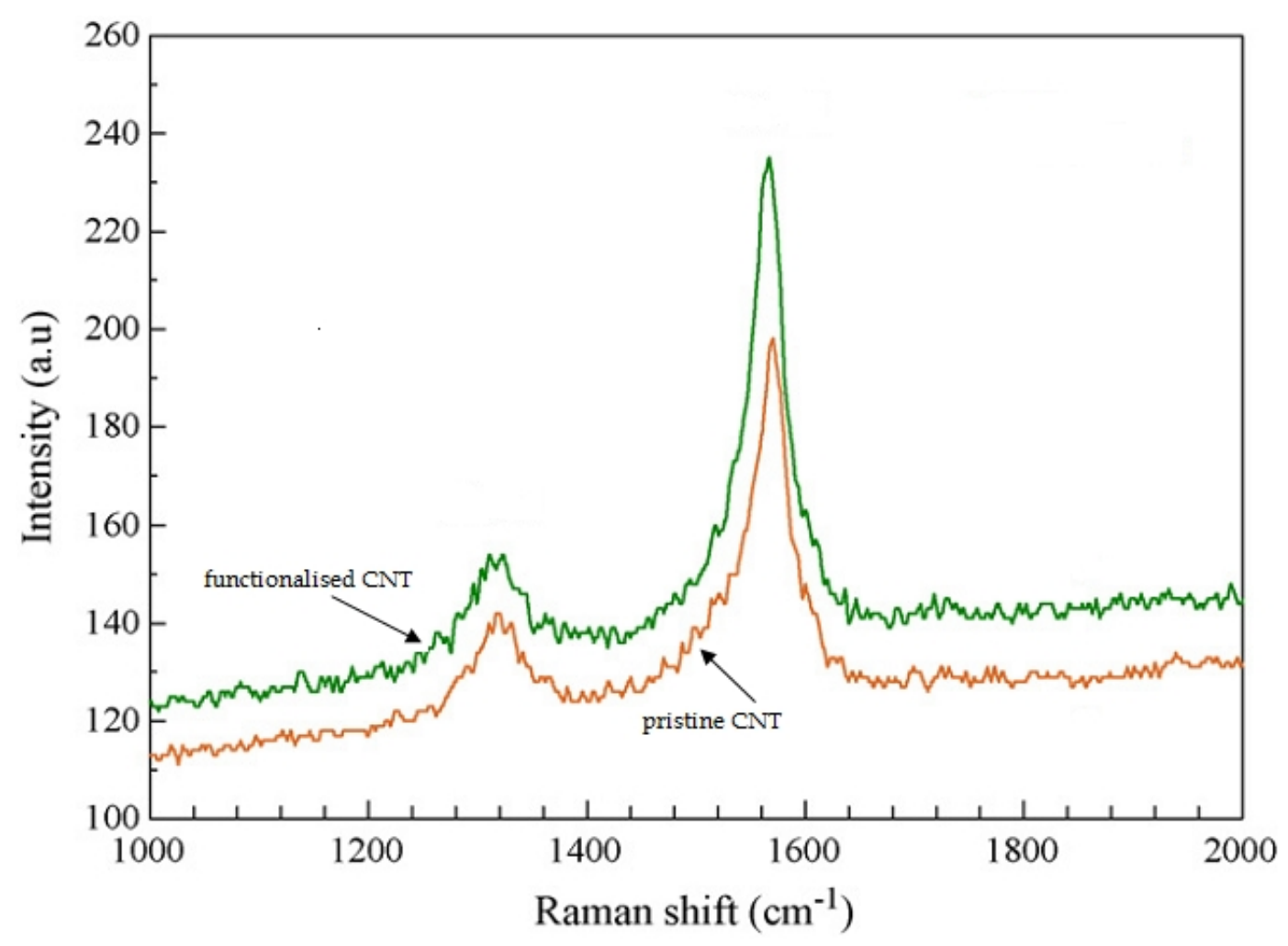

Fig. 3 - Raman spectra of pristine and acid functionalised CNTs

acid functionalised CNTs is higher than that of pristine CNTs. When comparing the values of the ratio $\mathrm{I}_{\mathrm{D}} / \mathrm{I}_{\mathrm{G}}$ for acid functionalized and pristine $\mathrm{CNTs}$, it is observed that after functionalisation, the ratio values increased. This is expected because the functionalisation of CNTs breaks some of its bonds and induces chemical groups that can be interpreted as defects on the structure (Osorio et al., 
2008; Su et al., 2010). In other words, there was an increase in the relative intensity of the disorder mode attributed to an increased number of $\mathrm{sp}^{3}$-hybridized carbons in the nanotube framework (Bahr and Tour, 2001). In the absence of quantitative methods, an increase in values of the ratio $\mathrm{I}_{\mathrm{D}} / \mathrm{I}_{\mathrm{G}}$ can actually be taken as a crude measure of the degree of functionalisation.

The infrared spectra of the pristine and acid functionalised CNTs are shown in Figure 4. The FT-IR is used to identify the existence or absence of functional groups on the surface of the CNTs. Infrared spectrum measures the quantity of radiation absorbed versus its frequency. When CNTs are submitted to an infrared radiation, the difference of charge state between carbon atoms induces the formation of an electric dipole; the appearance of these dipoles generates signals that are detected (Osorio et al., 2008). Atoms involved in stretch and bending vibrations usually determine the frequencies of absorption (Osorio et al., 2008).

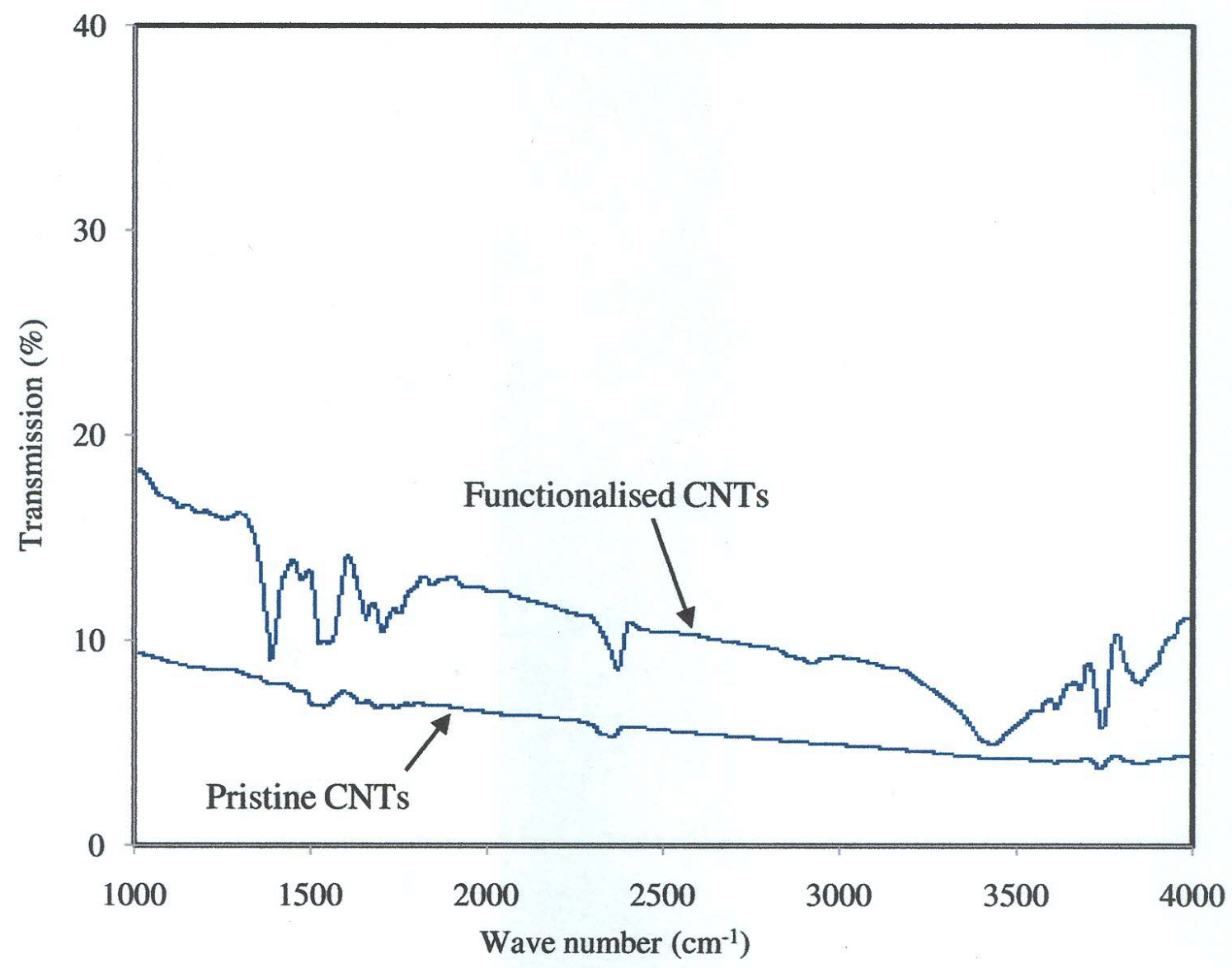

Fig. 4 - FT-IR spectra of pristine and acid functionalised CNTs 
The infrared spectrum of pristine CNTs has very low infrared absorption intensities, thus it shows no significant peaks. This is because the high symmetry present on pristine CNTs generates very weak infrared signals due to the weak difference of charge state between carbon atoms (Osorio et al., 2008). The weak difference of charge state leads to very small induced electric dipole, providing a silent spectrum (Osorio et al., 2008). As expected, it can be seen from Figure 4 that a number of infrared peaks are present in the infrared spectra for acid functionalised CNTs. Therefore, the FT-IR is in good agreement with results showed on Raman spectrometry. The presence of functional groups confirmed with FT-IR agrees with the higher ratio $\mathrm{I}_{\mathrm{D}} / \mathrm{I}_{\mathrm{G}}$, proving the addition of functional groups on the nanotubes.

Figure 4 itself present peaks at $1300-1750 \mathrm{~cm}^{-1}$, around $2300 \mathrm{~cm}^{-1}$ and $3400-4000 \mathrm{~cm}^{-1}$. The $1300-$ $1750 \mathrm{~cm}^{-1}$ range can be mainly attributed to acidic groups like carboxylic acids $(-\mathrm{COOH})$ and phenolic acids (O-H) (Li et al., 2002; $\mathrm{Lu}$ and $\mathrm{Su}, 2007)$. In particular, the peaks at 1310 and 1710 $\mathrm{cm}^{-1}$ may be attributed to acidic groups such as lactone or basic groups such as ketones, chromene and pyrones (Montes-Moran et al., 2004; Naseh et al., 2009). In addition, the signature of carbonyl $(>\mathrm{C}=\mathrm{O})$ appears at around $1750 \mathrm{~cm}^{-1}$ (Li et al., 2002). The $3400-4000 \mathrm{~cm}^{-1}$ range can be primarily related to hydroxyl groups (-OH) (Li et al., 2002; $\mathrm{Lu}$ and $\mathrm{Su}, 2007)$.

The functionalisation of carbon materials is used to obtain a more hydrophilic surface structure with relatively large number of oxygen containing surface groups (Li et al., 2002). These oxygencontaining groups behave as acids or bases, which possess ion exchange properties and improve the dispersibility of CNTs in liquids such as water (Li et al., 2002), i.e., the dissociation of the surface functional groups facilitates the dispersion by creating a negative or positive charge or providing hydrophilic sites on a hydrophobic surface (Boehm, 1994). Furthermore, the introduction of functional groups on the surface of CNTs as illustrated in Figure 4 provides several chemical sites for adsorption of colloidal particles from wastewater. As stated earlier, the adsorption of colloidal 
particles can lead to bridging flocculation and neutralisation of charges on the particles, thus facilitating agglomeration.

Assessing the nature of adsorption exclusively by the presence of specific functional groups is rather complex. In the case of flocculating negatively charged colloidal particles, the adsorption process might be due to the presence of basic groups such as carbonyl and hydroxyl groups. Considering the fact that the point of zero charge for acid functionalised CNTs (see discussion below) was 7.3, it means that the functional groups were weakly acidic or more basic in nature, e.g., carbonyl groups or hydroxyl. The carbonyl group is moderately polar indicating the presence of a slight negative charge on the oxygen $\left(\delta^{-}\right)$and a slight positive charge $\left(\delta^{+}\right)$on the carbon of the $\mathrm{C}=\mathrm{O}$ double bond. However, the sites responsible for the adsorption process might not be exclusively due to the basic groups, other sites on the CNTs can also contribute to the adsorption process and even physical adsorption is also possible.

Table 2 - The amount of functional groups on the surfaces of pristine and acid functionalised CNTs.

\begin{tabular}{lcc}
\hline CNT & Concentration of acidic sites $(\mathrm{mmol} / \mathrm{g})$ & Concentration of basic sites $(\mathrm{mmol} / \mathrm{g})$ \\
\hline Pristine & 0.120 & 0.216 \\
Functionalised & 2.751 & 4.310 \\
\hline
\end{tabular}

The Boehman's method (or the depletion technique) was used to qualitatively determine the surface concentrations of the acidic and basic sites on the CNTs in Table 2 (Boehm, 1966; Boehm, 1994). The procedure included the following typical steps ( $\mathrm{Lu}$ and $\mathrm{Su}, 2007$; Barton et al., 1997): (1) One hundred milligrams of the CNT was placed in a $100 \mathrm{~mL}$ flask containing $50 \mathrm{~mL}$ of $0.1 \mathrm{M} \mathrm{NaOH}$ and $0.1 \mathrm{M} \mathrm{HCl}$ solutions. (2) The flask was sealed and shaken for 48 hours, and then filtered through a $0.45 \mu \mathrm{m}$ Nylon fibre filter and $10 \mathrm{~mL}$ of each filtrate was pipetted. (3) The excess acid and base was titrated with $0.1 \mathrm{M} \mathrm{NaOH}$ and $0.1 \mathrm{M} \mathrm{HCl}$, respectively. (4) The concentration of acidic sites was 
determined from the amount of $\mathrm{NaOH}$ that reacted with the CNTs; while the concentration of the basic sites was determined from the amount of $\mathrm{HCl}$ that reacted with the CNTs. The quantity of functional groups in Table 2 is in good agreement with the FT-IR spectra. There is only trace amounts of functional groups present on pristine CNTs compared to acid functionalised CNTs.

From Table 2, it is seen that acid functionalised CNTs contain more basic functional groups than acidic functional groups. Therefore, the acid functionalised CNTs can exhibit considerable anion exchange capabilities, i.e., it can effectively function as a cationic coagulant in water and wastewater treatment. In other words, the basic sites would be responsible for adsorbing anions from aqueous solutions (Pereira et al., 2003; $\mathrm{Lu}$ and $\mathrm{Su}, 2007$ ). On the other hand, the acidic sites would be responsible for adsorbing cations (Pereira et al., 2003; Lu and Su, 2007). The phenomena of basicity as applied to adsorption are described in Equations 1 to 3 (Leon et al., 1992).

$$
\begin{aligned}
& \mathrm{S}_{\mathrm{B}}+\mathrm{H}^{+} \square \quad \mathrm{HS}_{\mathrm{B}}^{+} \\
& -\mathrm{COH}+\mathrm{H}^{+} \square \quad \mathrm{C}^{+}+\mathrm{H}_{2} \mathrm{O} \\
& -\mathrm{COH}+\mathrm{H}^{+} \square \quad \mathrm{COH}_{2}^{+}
\end{aligned}
$$

In Equations (2) and (3), the basic properties are implicitly restricted to hydroxyl type groups or at most, extended to include other oxygen functional groups as well (Leon et al., 1992). These expressions are useful to understand the phenomena of adsorption in practice.

Table 3. Physicochemical properties of CNTs.

\begin{tabular}{lcc}
\hline Property & Pristine & Acid functionalised \\
\hline Surface area $\left(\mathrm{m}^{2} / \mathrm{g}\right)$ & 499 & 601 \\
Pore volume $\left(\mathrm{cm}^{3} / \mathrm{g}\right)$ & 0.64 & 0.93 \\
\hline
\end{tabular}


The physicochemical characteristics of the CNTs are presented in Table 3. From the table, it can be seen that both the specific surface area and pore volume are higher for acid functionalised CNTs than the pristine CNTs. Since the CNTs tend to form long bundles stabilised by numerous $\Pi-\Pi$ interaction between the tubes (Naseh et al., 2009), the inclusion of functional groups on the surface of nanotubes generates repulsion force, which leads to de-bundling of nanotubes and, therefore, causes surface area increases (Naseh et al., 2009; Rurlle et al., 2007).

The $\mathrm{pH}$ value at which the zeta potential $(\zeta)$ equals to zero is called the point of zero charge (PZC) or the isoelectric point (IEP). It is used to assess the adsorbent surface charge qualitatively. At $\mathrm{pH}<$ $\mathrm{PZC}$, the surface of the adsorbent is positively charged and is accessible to anions; at $\mathrm{pH}=\mathrm{PZC}$, the surface is neutral; and at $\mathrm{pH}>\mathrm{PZC}$, the surface is negatively charged and will repel the anions. The mass titration results for acid functionalised CNTs are shown in Figure 5. A plateau is obtained in this plot of $\mathrm{pH}$ versus mass fraction. By taking the average value of the three asymptotic $\mathrm{pH}$ values (i.e., asymptotes to $\mathrm{x}$-axis), the $\mathrm{pH}$ of the PZC for functionalised CNTs was found to be 7.3. Therefore, it is obvious that the acid functionalised CNTs were basic in nature. This indicates that very little acidic functional groups such as carboxylic groups have been added on the surface of CNTs. This concurs well with the amount of acidity compared to basicity of the functionalised CNTs shown in Table 2, i.e., there are more basic groups than acidic groups. With the PZC of 7.3, it makes the functionalised CNTs more appropriate for the heterogeneous coagulation of brewery wastewater, which has a zeta potential of $-38 \mathrm{mV}$ (see Table 1). With a negative zeta potential brewery wastewater is considered to be having predominantly negatively charged colloidal particles. 


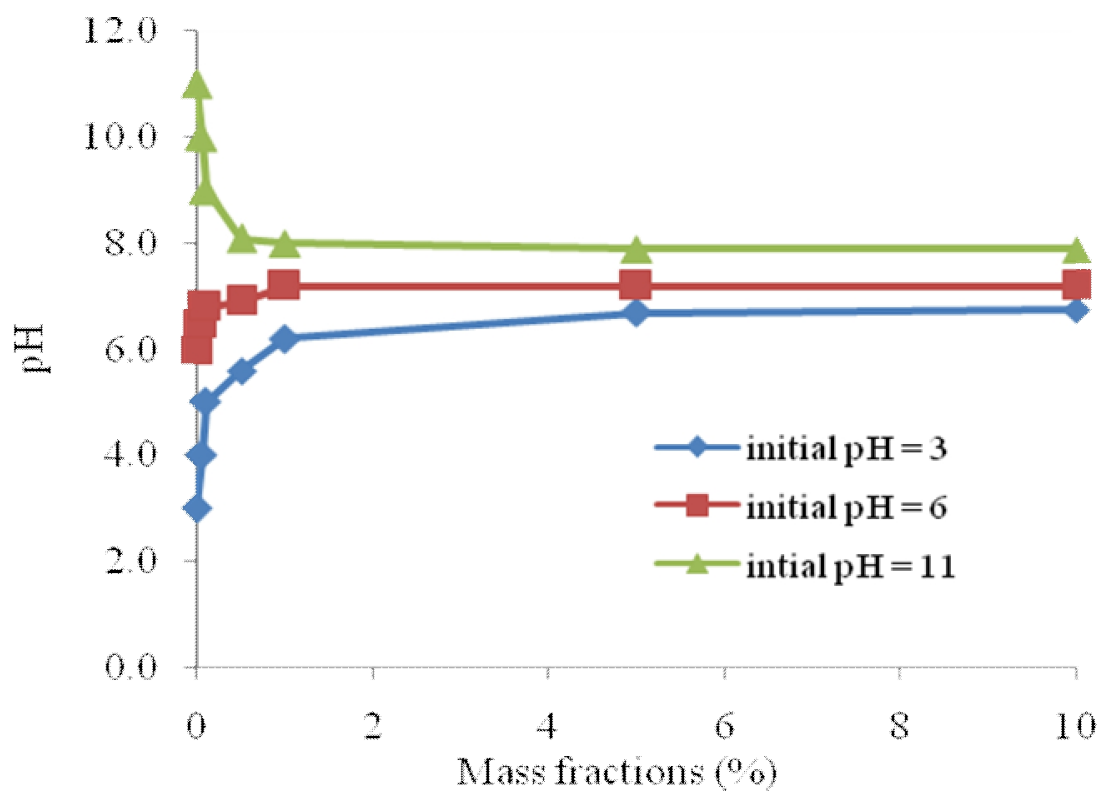

Fig. 5. Mass titration results for acid functionalised CNTs

\subsection{Coagulation and flocculation studies}

It is widely agreed that particles smaller than $10^{-7} \mathrm{~m}$ form stable colloids and their separation from wastewater is very difficult (Klimiuk et al., 1999). It is also well known that coagulation and flocculation are the standard techniques in the wastewater industry for removal of colloidal particles. The mechanism of coagulation and flocculation are based on destabilisation of the structure of colloidal particles, which subsequently allows their aggregation and separation from the solution (Klimiuk et al., 1999). In general, coagulation is a process where the repulsive potential of electrical double layer of colloids is reduced in such a way that micro-particles can be produced. Subsequently, the micro-particles collide with each other and form larger structures (flocs) in the flocculation process (Matilainen et al., 2010).

In this study, the phenomena of heterogeneous coagulation and flocculation will be applied. Since the colloidal particles found in brewery wastewater are negatively charged (see Table 1), positively charged CNTs or basic type CNTs would be suitable for heterogeneous coagulation with the 
colloidal particles in the wastewater. Based on the authors' review of the current literature as at the time of writing this paper, there was no data found that evaluates the application of CNTs as heterogeneous coagulants, including comparison with traditional flocculants such as ferric chloride. In this section, the effects of $\mathrm{pH}$ and dosage using various coagulants (pristine CNTs, acid functionalised CNTs and ferric chloride) on some characteristics of brewery wastewater (see Table 1) are discussed. The performance or removal efficiencies $(E)$ of the heterogeneous coagulation and flocculation processes were in some cases determined according to Equation 4 below:

$$
E=\frac{C_{i}-C_{f}}{C_{i}} \times 100
$$

where, $C_{i}$ and $C_{f}$ are the initial and final values of various brewery wastewater characters, respectively.

\subsubsection{Comparison of CNTs and ferric chloride}

The objective of this work is to access the suitability of using CNTs as heterogeneous coagulants and/or flocculants in the treatment of brewery wastewater. As a result, a comparison on the effectiveness of coagulation and/or flocculation is made between CNTs and ferric chloride. As mentioned earlier (section 2.1), ferric chloride was chosen amongst other inorganic coagulants such as alum because it is effective over a wider $\mathrm{pH}$ range of $4-11$, and that the ferric hydroxide floc is heavier than alum, thus improving its settling characteristics (Ebeling et al., 2003). The initial evaluation of the coagulation process was determined by analysis of turbidity as it has been used as a measure of water quality for many years. In fact, the turbidity of raw water is the targeted substance that is removed during coagulation-sedimentation treatment (Anadurai et al., 2004), and that turbidity is an important parameter for checking the efficiency of coagulation (Cheng et al., 2005). Turbidity is a principal physical characteristic of water, which is an expression of the optical property that causes light to be scattered and absorbed by particles and molecules rather than 
transmitted in straight lines through a water sample. In simple terms, turbidity is the cloudiness of water. The higher the turbidity, the harder it is to see through the water. It is caused by suspended matter or impurities that interfere with the clarity of the water. These impurities may include clay, silt, finely divided inorganic and organic matter, soluble coloured organic compounds, plankton, and other microscopic organisms.

Once it has been established that CNTs can coagulate and/or flocculate brewery wastewater, the rest of the studies that followed were based on acid functionalised CNTs as may be seen in the subsequent sections.

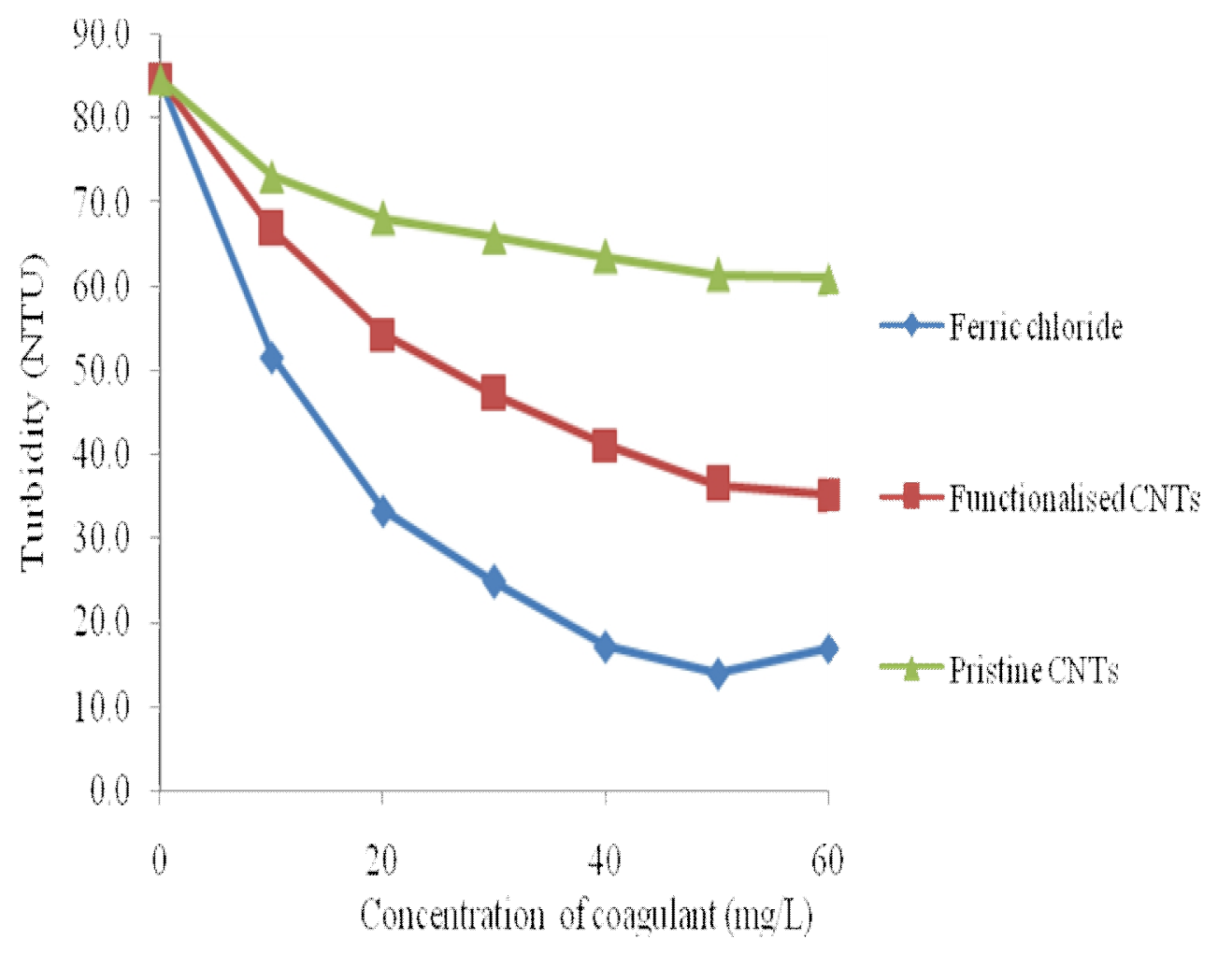

Fig. 6 - Comparison of CNTs and ferric chloride on removal of turbidity at standard conditions (flash mixing speed of $150 \mathrm{rpm}$ for 3 minutes; slow mixing speed of $60 \mathrm{rpm}$ for 20 minutes).

Figure 6 shows a comparison of the effectiveness of CNTs and ferric chloride in removing turbidity from brewery wastewater. An overview of the figure shows that all the three coagulants are able to remove turbidity to a certain extent. However, ferric chloride was found to display higher efficiency 
than CNTs for the coagulation/flocculation of colloidal matter in brewery wastewater. This may be attributed to the fact that several flocculation mechanisms may have been simultaneously involved when ferric chloride is used, i.e., (1) adsorption/ charge neutralisation, and (2) sweep-floc coagulation (or enmeshment). Sweep-floc coagulation is significant and is more likely to have predominated because ferric chloride doses used in this investigation may have significantly exceeded the solubility limit. In sweep-floc coagulation, metal hydroxide precipitates promote coagulation by increasing the interparticle collision rate and enmeshing suspended particles (Childress et al., 1999). As for CNTs, the most probable mechanisms are (1) adsorption/charge neutralisation, and (2) adsorption and interparticle bridging. These are not likely to have a high impact for CNTs. For example, adsorption and interparticle bridging is likely to be insignificant because CNTs do not form several long chains. Furthermore, the charge density may not have been as high as that for ferric ions for effective charge neutralisation to occur.

One interesting observation to note is that acid functionalised CNTs performed better than pristine CNTs. This is a good confirmation that acid functionalised CNTs indeed possessed basic (or positively charged) functional groups as shown in Table 2. Nevertheless, the results suggest that the colloids were, to a certain degree, destabilised by pristine CNTs and as a result were forced to agglomerate, hence the considerable reduction in turbidity. These results indicate that though pristine CNTs were found not to possess significant peaks (Figure 4), they were partially oxidised due to high temperatures during their production. Furthermore, it is also noted that basic surface oxides are always present on carbon surfaces, and that oxidised carbons always contain basic sites (Boehm, 1994). Therefore, these basic surface groups could have contributed to the coagulation of colloidal particles from brewery wastewater. 

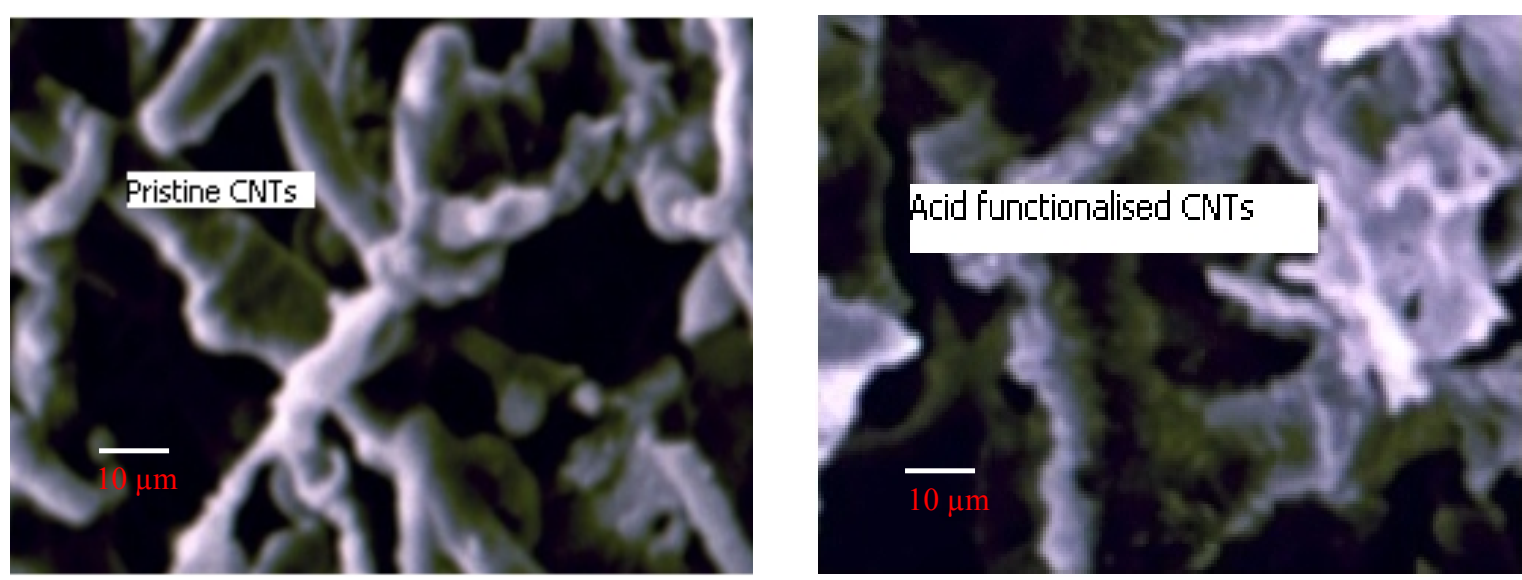

Fig. 7 - Electron micrographs showing colloidal materials on CNTs after coagulation/flocculation at 5000x of magnification

Figure 7 shows SEM images which compare the surface morphologies of pristine and acid functionalised CNTs after the coagulation/flocculation test works. It can be seen from the figure that acid functionalised CNTs are intensely covered by colloidal matter compared to pristine CNTs. This is in agreement with Figure 6, which shows that acid functionalised CNTs perform better than pristine CNTs.

Since these results have established that acid functionalised CNTs can act as heterogeneous coagulants, a series of tests that followed were conducted with acid functionalised CNTs only (unless stated otherwise). Furthermore, the study involved the expansion of coagulation objectives from turbidity removal only to include COD removal as well. In the brewery industry, COD is the most important parameter for recycling water or is required to be measured at all times (Ince et al., 2000; Braeken et al., 2004; Simate et al., 2011). The COD is defined as a measure of the oxygen equivalent of the organic matter content of a sample that is susceptible to oxidation by a strong oxidant (Clesceri et al., 1998). 


\subsubsection{Effect of $p H$ on coagulation}

The $\mathrm{pH}$ of the solution is an important parameter and, therefore, plays a preponderant role in the coagulation and flocculation process. It affects both the surface charge density of the colloid and the action of the coagulant (e.g., degree of ionization, charge density, speciation, etc). For example, the colloidal particles possess positive charges at low $\mathrm{pH}$ and negative charges at high $\mathrm{pH}$. Furthermore, $\mathrm{pH}$ is an important factor that affects the dissociation of functional groups contained on CNTs (Kuo and Lin, 2009).

\section{Variation of the zeta potential}

Zeta potential is defined as the potential at the boundary of the hydrodynamic shear plane of a charged particle (Lin et al., 2003). This parameter is particularly important in that it relates to the degree of repulsion or attraction a suspended particle in a liquid has with other particles or with charged surfaces. In addition, it is the magnitude of the zeta potential that determines the extent of interaction between colloids and other surfaces. This means that high zeta potential values provide greater colloidal stability (by way of increased electrostatic repulsion between charged surfaces). As alluded to earlier, the point at which the zeta potential switches its sign from negative to positive is called the PZC (or IEP), and it is in this area that the colloidal particles possess the lowest stability, and hence the greater chance of aggregation or deposition (Rodriguez-Santiago et al., 2008). 


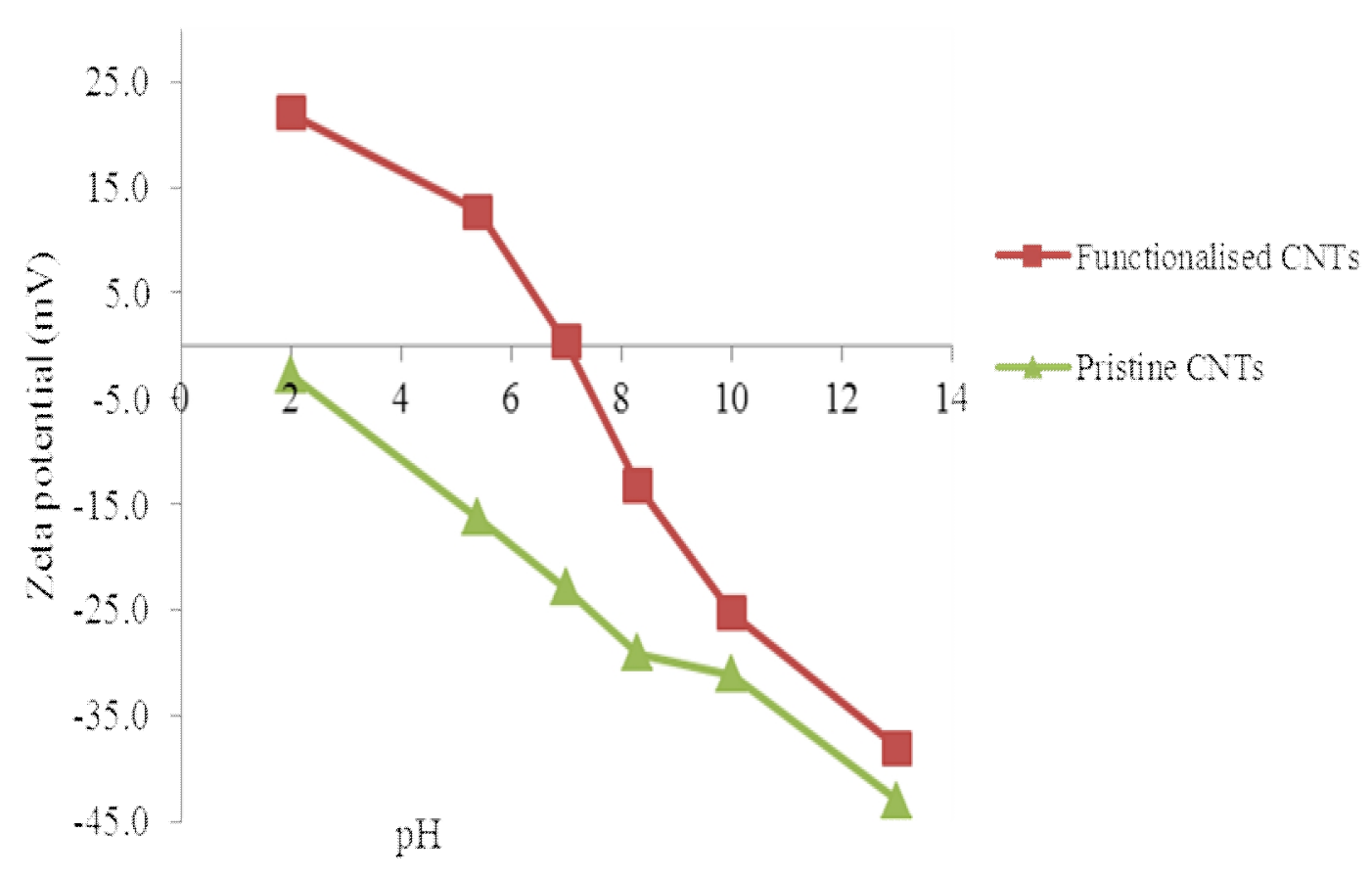

Fig. 8 - Zeta potential of pristine and acid functionalised CNTs

The zeta potential of charged particles is influenced not only by the surface charge on the particle, but also by the environmental conditions in which the particles are suspended (e.g., pH, conductivity, temperature, ion concentration, etc). Therefore, $\mathrm{pH}$ (at a fixed temperature of $25^{\circ} \mathrm{C}$ ) was chosen as the main tool to vary the zeta potential of CNTs. The zeta potential of pristine and acid functionalised CNTs at various pHs are shown in Figure 8. As can be seen from the figure, the zeta potential of both the pristine and acid functionalised CNTs decrease with an increase in $\mathrm{pH}$. The figure confirms the results of Figure 5 that the PZC for acid functionalised CNTs occurs at a $\mathrm{pH}$ of about 7.3, whereas, the zeta potential of pristine CNT was negative throughout the $\mathrm{pH}$ studied, and no PZC value was observed. The acid functionalised CNTs have positive zeta potentials at $\mathrm{pHs}<7.3$, which indicates that they are positively charged and negative zeta potential at $\mathrm{pHs}>7.3$, implying that they are negatively charged. These results show that at $\mathrm{pH}<\mathrm{PZC}$, there will be electrostatic interactions between the positively charged CNTs and the negatively charged colloidal particles in the brewery wastewater. The electrostatic interactions can facilitate adsorption 
and charge neutralisation of the colloidal particles leading to the coagulation and flocculation of the colloidal particles.

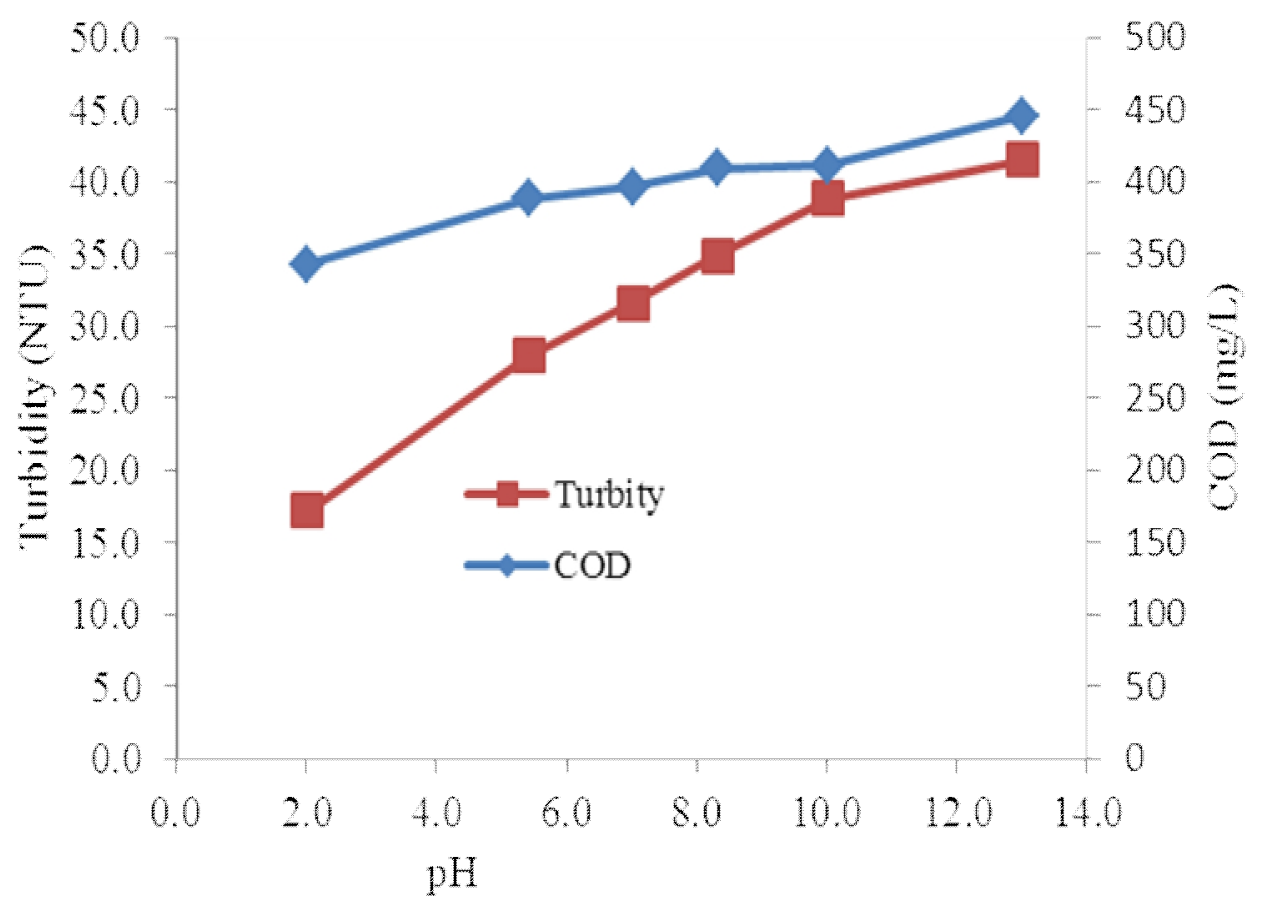

Fig. 9 - Effect of $\mathrm{pH}$ on turbidity and COD reduction

\section{Variation of turbidity and chemical oxygen demand}

The effect of initial $\mathrm{pH}$ on turbidity and COD removal is shown in Figure 9. The figure shows that turbidity removal is $\mathrm{pH}$ dependent. Turbidity removal by acid functionalised CNTs decreases with an increase in $\mathrm{pH}$, and vice-versa. The dependence of turbidity removal on $\mathrm{pH}$ is due to the dependence of the surface charge of acid functionalised CNTs on $\mathrm{pH}$ values that have been shown by the zeta potential values in Figure 8 . At $\mathrm{pH}<\mathrm{PZC}$, the $\mathrm{H}^{+}$ions adsorb onto the surface of CNTs rendering the surface charges of acid functionalised CNTs to be positive. Therefore, coulombic attractions can take place between the positively charged acidified CNTS and the negatively changed colloidal particles. At higher $\mathrm{pH}$, the surface charges of CNTs become more negative because of the deposition of more $\mathrm{OH}^{-}$on the CNT surface, thus increasing electrostatic repulsion between the negatively charged colloidal particles. Therefore, the turbidity removal decreases at $\mathrm{pH}$ $>$ PZC due to the negatively charged acid functionalised CNTs. 
A similar trend to turbidity removal (see Figure 9) was also observed for the COD removal, i.e., removal decreases with an increase in the $\mathrm{pH}$ value and vice-versa.

\subsubsection{Effect of dosage}

To investigate the effect of dosage, $100 \mathrm{~mL}$ of brewery wastewater was mixed with different doses of acid functionalised CNTs, while keeping other parameters as constants. The results of the effect of varying the dosage on turbidity and COD removal are shown in Figure 10.

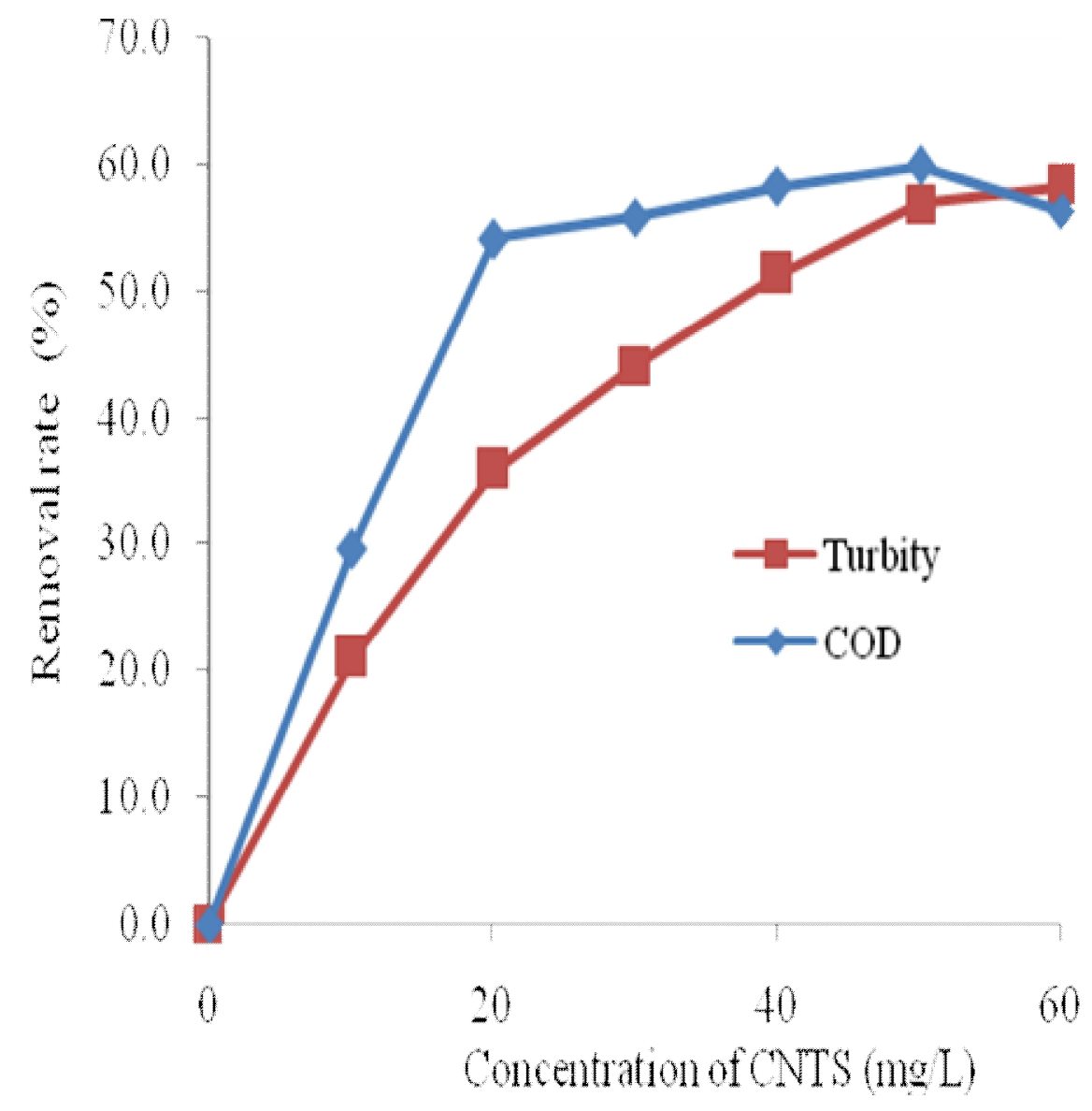

Fig. 10 - Effect of CNT dosage on turbidity and COD removal

Figure 10 shows that there is a significant reduction in turbidity and COD up to dosages of about 40-50 mg/L. Beyond this value, the rate of turbidity and COD removal is small. This is in contrast to the fact that with more CNTs, more charged sites are available for uptake of colloidal particles from the brewery wastewater. A possible explanation is that increased amounts of CNTs beyond a 
certain level may favour competitive CNT-CNT associations at the expense of CNT-colloidal particle interactions. These results imply that the mechanisms of coagulation by CNTs may be similar to those by polymers. This is because low dosages of polymers have been found to achieve a fast and efficient removal of colloids as observed by Roussy et al. (2004) and Assaad et al. (2007).

However, since the turbidity and COD decreased consistently as the dosage of acid functionalised CNTs increased, it would be expected that charge neutralisation played a key role in the heterogeneous coagulation of colloidal particles.

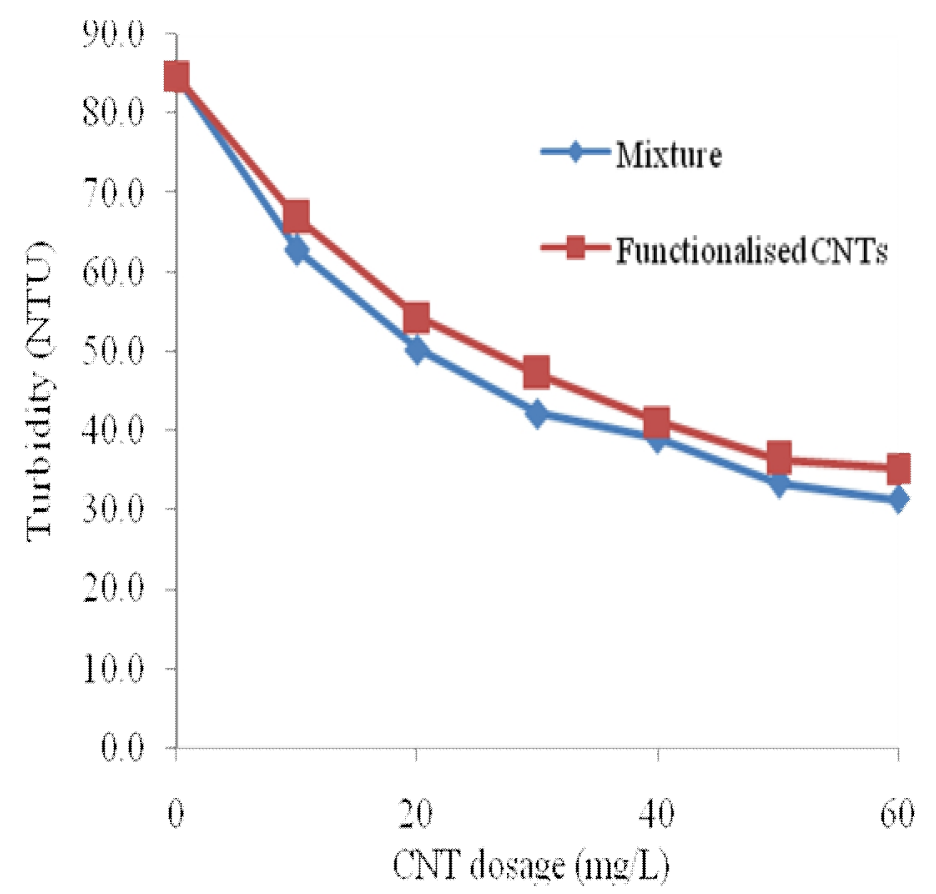

Fig. 11 - Effect of a mixture of CNTs and ferric chloride on turbidity; ferric chloride $=2 \mathrm{mg} / \mathrm{L} ; \mathrm{pH}=6.5$.

\subsubsection{Mixture of CNTs and ferric chloride}

The overall degree of turbidity (or COD) removal by acid functionalised CNTs was not sufficiently high compared to ferric chloride (see Figure 6). In order to explore the coagulation efficiency further, acid functionalised CNTs were used in conjunction with ferric chloride. Therefore, synergic effect of a mixture of acid functionalised CNTs and ferric chloride was investigated. The results of this evaluation are shown in Figure 11. 
It can be seen from Figure 11 that the turbidity removal only improved slightly at all dosages of CNTs. Therefore, it is difficult to distinguish the contribution of a mixture of acid functionalised CNTs and ferric chloride from the results presented in Figure 11. However, the results may be explained as follows: (1) the flocculation capability of ferric chloride was suppressed by the adsorption of ferric ions onto some 'negative sites' of CNTs, and (2) the presence of repulsive effects between positively charged ferric ions and CNTs.

\subsubsection{Mechanisms of heterocoagulation}

This section discusses the mechanisms by which the heterogeneous coagulation of colloidal particles is occurring. The knowledge of the mechanism is paramount for understanding the design, operation and control of the separation processes at industrial scale. To better understand the coagulation and flocculation mechanism, in this work, it was essential to study the evolution of zeta potential of the flocculated colloidal particles as a function of CNT dosage. Prior to the test work, the $\mathrm{pH}$ of the brewery wastewater was adjusted to 6.5 at which the colloidal particles were still moderately negatively charged $(-25.5 \mathrm{mV})$ and the CNTs were positively charged.

The evolution of zeta potential of brewery wastewater as a function of CNT dosages is shown in Figure 12. It can be seen from the figure that the magnitude of the negative zeta potential decreases with an increase in the dosage of CNTs. In other words, there is an increase in zeta potential with an increase in CNT dosage, and that the increased zeta potential remained positive. The increase in zeta potential by CNTs was high enough to make coagulation by charge neutralisation. Charge neutralisation is caused by the reduction in the electric double layer repulsion between particles due to adsorption of coagulants on oppositely charged particles (Zhou and Franks, 2006). Therefore, these results show that the heterogeneous coagulation of colloidal particles by acid functionalised CNTs in brewery wastewater occurs by the mechanisms of charge neutralisation. These results are 
in agreement with the deduction in section 3.2.3 about the heterogeneous coagulation mechanism; turbidity and COD removal increased with an increase in dosage. From Figure 12 it can be seen that the isoelectric point was reached at $\sim 25 \mathrm{mg} / \mathrm{L}$ of the CNTs.

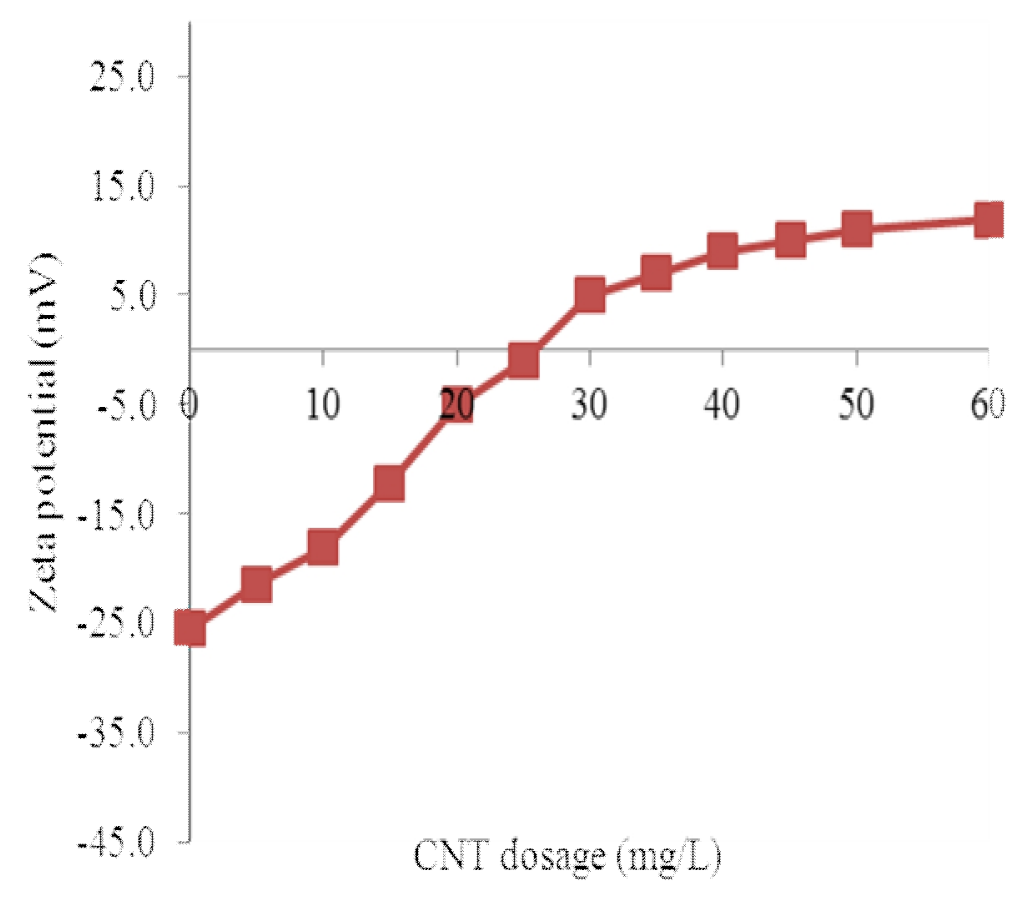

Fig. 12 - Electrokinetic zeta potential of brewery wastewater as a function of CNT dosage.

\section{Challenges and future prospects}

A lot of challenges arise in attempting to use CNTs in their present state as coagulants or flocculants. Firstly, the CNTs lack dispersion and solubility properties. In recent years, however, there have been several successful attempts to prepare water soluble CNTs by various techniques (Zhang et al., 2009; Pei et al., 2008), and improvements in their dispersivity through functionalisation (Zhang et al., 2002). However, converting CNTs to complete water soluble form is not recommended since it poses practical difficulties of using them as adsorbent media (Upadhyayula et al., 2009). Nevertheless, dispersivity of CNTs is important because the benefit of water soluble CNTs can be exploited further in the fabrication of CNT composite membranes (Upadhyayula et al., 2009). On the other hand, semi dispersible and partially hydrophobic CNTs 
exhibit greater affinity towards bacteria than both completely dispersed or weakly dispersed CNTs (Upadhyayula et al., 2009). Secondly, the CNTs are very expensive, thus they require to be regenerated after use. If the CNTs are applied in the form of slurry, an efficient separation process downstream such as membrane filtration is needed to retain and recycle the CNTs. Thirdly, and most importantly, CNTs have potential impacts on human health and ecosystems (Moore, 2006; Smart et al., 2006; Wiesner, 2006; Simate et al., 2012). Whilst in use, CNTs may escape from the treatment system and enter the product water as residual CNTs (Simate et al., 2012). It is the residual CNTs that are of concern to human health (Simate et al., 2012). The residual CNTs can be ingested into the gastrointestinal tract to various organs through drinking water contaminated with CNTs (Simate et al., 2012). Some of the health effects associated with CNTs include cancer, granulomas and, inflammation and fibrosis, etc (Lam et al., 2006; Simate et al., 2012).

In view of the apparent human health effects of CNTs, it is important that their use is limited or measures are taken for their removal in water treatment operations. A comparative study on the adsorption/desorption properties of natural dissolved organic matter (NDOM) between CNTs and granular activated carbon (GAC) revealed that the CNTs have better adsorption performance and show less weight loss and reactivation than the GAC ( $\mathrm{Su}$ and $\mathrm{Lu}, 2007)$. The negligible weight loss is beneficial from two aspects (Upadhyayula et al., 2009). Firstly, the low replenishment of the material would balance out the high investment costs of CNT filters. Secondly, the release of CNTs (in immeasurable amounts) from the filters may not be a hazardous concern to the human, environment and ecosystem.

The CNTs may be removed from water using two methods (Simate et al., 2012). The first method is called membrane filtration, i.e., it constrains the particles by a membrane and the liquid is allowed to flow freely through the membrane. In the second method called ultracentrifugation, the liquid is constrained in a rotating vessel, and the particles move freely within the liquid by an external field 
of acceleration caused by the ultra-centrifugal field. These methods have been used quite extensively in the separation of macromolecules and molecules from liquids, and they are also presently becoming important in the separation of nanoparticles from liquids.

\section{Conclusions}

Research on CNTs has opened new avenues and applications in materials science. In this study, we have demonstrated one other new application of CNTs - heterogeneous coagulation and flocculation of colloidal particles from brewery wastewater. Previous studies have shown that CNTs are superior sorbents for various contaminants. On the other hand, the results of this study have shown that colloidal particles may be removed from brewery wastewater through heterogeneous coagulation. Therefore, by applying positively charged CNTs to brewery wastewater, it is expected that soluble pollutants can be adsorbed as shown from previous studies; and at the same time, colloidal particles can be removed through heterogeneous coagulation, which results from surface charge neutralisation between CNTs and colloidal particles.

Since the results of this work showed that there was no synergetic effect between CNTs and ferric chloride, the two should not be used as coagulants together. Instead an integrated process should use ferric chloride as a coagulant and CNTs as adsorbent or granular filtration media in later stages.

\section{Acknowledgements}

The authors wish to thank Dr. Lubinda F. Walubita of TTI - The Texas A\&M University System (USA) for his insightful technical comments on the paper. The financial support from the University of the Witwatersrand Staff Bursary is gratefully acknowledged. 


\section{Disclaimer}

The contents of this paper reflect the views of the authors who are responsible for the facts and accuracy of the data presented herein and do not necessarily reflect the official views or policies of any agency or institute. This paper does not constitute a standard, specification, nor is it intended for design, construction, bidding, or permit purposes. Trade names were used solely for information and not for product endorsement.

\section{References}

Abdessemed, D., Nezzal, G., Aim, R. B., 2000. Coagulation-adsorption-ultrafiltration for wastewater treatment and reuse. Desalination 131, 307-314.

Amuda, O. S., Alade, A., 2006. Coagulation/flocculation process in the treatment of abattoir wastewater. Desalination 196, 22-31.

Annadurai, G., Sung, S. S., Lee, D. J., 2004. Simultaneous removal of turbidity and humic acid from high turbidity stormwater. Advances in Environmental Research 8, 713-725.

Assaad, E., Azzouz, A., Nistor, D., Ursu, A. V., Sajin, T., Miron, D. N., Monette, F., Niquette, P., Hausler, R., 2007. Metal removal through synergic coagulation-flocculation using an optimised chitosan-montrollonite system. Applied Clay Science 37, 258-274.

Barrera-Díaz, C., Linares-Hernández, I., Roa-Morales, G., Bilyeu, B., Balderas-Hernández, P., 2009. Removal of biorefractory compounds in industrial wastewater by chemical and electrochemical pretreatments. Industrial and Engineering Chemistry Research 48(3), 1253-1258. 
Barton, S.S., Evans, M. J. B., Halliop, E., MacDonald, J. A. F., 1997. Acidic and basic sites on the surface of porous carbon. Carbon 35(9), 1361-1366.

Bernard, C., Herviou, P., Poujol, T., 1995. Stormwater treatment by dissolved air flotation: first results from a pilot project. Water Science Technology 32(1), 137-143.

Boehm, H.P., 1966. Chemical identification of surface groups. In: Eley, D.D., Pines, H., Weisz, P. B. (Editors), Advances in Catalysis 16. Academic Press, New York, pp. 179-287.

Boehm, H. P, 1994. Some aspects of the surface chemistry of carbon blacks and other carbons. Carbon 32(5), 759-769.

Braeken, L., Van der Bruggen, B., Vandecasteele, C., 2004. Regeneration of brewery waste water using nanofiltration. Water Research 38(13), 3075-3082.

Brukh, R., Mitra, S., 2007. Kinetics of carbon nanotube oxidation. Journal of Materials Chemistry 17, 619-623.

Cheng, W. P.,Chi, F. H., Yu, R. F., Lee, Y. C., 2005. Using chitosan as a coagulant in recovery of organis matters from the mash and lauter wastewater of brewery. Journal of Polymers and the Environment 13 (4), 383-388.

Childress, A.E., Vrijenhoek, E.M., Elimelech, M., Tanaka, T. S., Beuhler, M. D., 1999. Particulate and THM precursor removal with ferric chloride. Journal of Environmental Engineering 125(11), 1054-1061. 
Chuang, S.H., Chang, T.C., You, S.J., Ouyang, C.F., 2005. Evaluation of wastewater reclamation processes in a high-tech industrial park. Desalination 175, 143-152.

Clesceri, L. S., Greenberg, A. E., Eaton, A. D., 1998 (Editors). Standard methods for the examination of water and wastewater, 20th edition. American Public Health Association, Washington DC.

Cortes, P., Deng, S., Camacho, L., Smith, G. B., 2010. The adsorption properties of bacillus atrophaeus spore on functionalised carbon nanotubes. Journal of Sensors 2010, 143-152.

Dresselhaus, M. S., Eklund, P. C., 2000. Phonons in carbon nanotubes. Advances in Physics 49, 705-814.

Ebeling, J. M., Sibrell, P. L., Ogden, S. R., Summerfelt, S. T., 2003. Evaluation of chemical coagulation-flocculation aids for the removal of suspended solids and phosphorus from intensive recirculating aquaculture effluent discharge. Aquacultural Engineering 29, 23-42.

Féris, L. A., Rubio, J., 1999. Dissolved air flotation (DAF) performance at low saturation pressures. Filtration and Separation 36(9), 61-65.

Goering, J., Burghaus, U., 2007. Adsorption kinetics of thiophene on single-walled carbon nanotubes (CCNTs). Chemical Physics Letters 447, 121-126. 
González-Guerrero, A. B., Mendoza, E., Pellicer, E., Alsina, F., Fernández-Sánchez, C., Lechuga, L. M.., 2008. Discriminating the carboxylic groups from the total acidic sites in oxidized multiwall carbon nanotubes by means of acid-base titration. Chemical Physics Letters 462, 256-259.

Gregory. J., 2006. Particles in water: properties and processes. IWA Publishing/CRC Press, London.

Ince, B. K., Ince, O., Sallis, P. J., Anderson, G. K., 2000. Inert COD production in a membrane anaerobic reactor treating brewery wastewater. Water Research 34(16), 3943-3948.

Iyuke, S. E., Simate, G. S., 2011. Synthesis of carbon nanomaterials in a swirled floating catalytic chemical vapour deposition reactor for continuous and large scale production, In: Naraghi. M. (Editor), Carbon Nanotubes - Growth and Applications. In-Tech, Rijeka, pp 35-58.

Klimiuk, K., Filipkowska, U., Korzeniowska, A., 1999. Effects of pH and coagulant dosage on effectiveness of coagulation of reactive dyes from model wastewater by polyaluminium chloride. Polish Journal of Environmental Studies 8(2), 73-79.

Kuo, C. Y., Lin, H. Y., 2009. Adsorption of aqueous cadmium (II) onto modified multi-walled carbon nanotubes following microwave/chemical treatment. Desalination 249, 792-796.

Leon, C. A., Solar, J. M., Calemma, V., Radovic, L. R., 1992. Evidence for the protonation of basal plane sites on carbon. Carbon 30 (5), 797-811.

Li, Y. H., Xu, C., Wei, B., Zhang, X., Zheng, M., Wu, D., Ajayan, P. M., 2002. Self-organized ribbons of aligned carbon nanotubes. Chemistry of Materials 14, 483-485. 
Li, Y-H., Wang, S., Zhang, X., Wei, J., Xu, C., Luan, Z., Wu, D., 2003(a). Adsorption of fluoride from water by aligned carbon nanotubes. Materials Research Bulletin 38(3), 469-476

Li, Y-H., Ding, J., Luan, Z., Di, Z., Zhu, Y., Xu, C, Wu, D., Wei, B., 2003(b). Competitive adsorption of $\mathrm{Pb}^{2+}, \mathrm{Cu}^{2+}$ and $\mathrm{Cd}^{2+}$ ions from aqueous solutions by multiwalled carbon nanotubes. Carbon 41, 278-2792.

Li, Y-H., Zhu, Y., Zhao, Y., Wu, D., Luan, Z., 2006. Different morphologies of carbon nanotubes effect on the lead removal from aqueous solution. Diamond and Related Materials 15, 90-94.

Li, Y-H., Zhao, Y. M., Hu, W. B., Ahmad, I., Zhu, Y. Q., Peng, J. X., Luan, Z. K., 2007. Carbon nanotubes - the promising adsorbent in wastewater treatment. Journal of Physics: Conference Series 61, 698-702.

Liew, A. G., Noor, M. J. M. M., Muyibi, S. A., Fungara, A. M. S., Muhammed, T. A., Iyuke, S. E., 2006. Surface water clarification using M. oleifera seeds. International Journal of Environmental Studies 63(2), 211-219.

Lin, C-F., Liu, S-H., Hao, O. J., 2001. Effect of functional groups of humic substances on UF performance. Water Research 35(10), 2395-2402.

Lin, D.Q., Brixius, P.J., Hubbuch, J.J., Thommes, J., Kula, M.R., 2003. Biomass/adsorbent electrostatic interactions in expanded bed adsorption: A zeta potential study. Biotechnology and Bioengineering 83(2), 149-157. 
Lu, C., Chung, Y-L., Chang, K-F., 2005. Adsorption of trihalomethanes from water with carbon nanotubes. Water Research 39, 1183-1189.

Lu, C., Su, F., 2007. Adsorption of natural organic matter by carbon nanotubes. Separation and Purification Technology 58, 113-121.

Madwar, K., Tarazi, H., 2002. Desalination techniques for industrial wastewater reuse. Desalination $152,325-332$.

Matilainen, A., Vepsäläinen, M., Sillanpää, M., 2010. Natural organic matter removal by coagulation during drinking water treatment: a review. Advances in Colloid and Interface Science 159, 189-197.

Montes-Moran, M. A., Suarez, D., Menendez, J. A., Fuente, E., 2004. On the nature of basic sites on carbon surfaces: an overview. Carbon 42, 1219-1225.

Moore, M. N., 2006. Do nanoparticles present ecotoxicological risks for the health of the aquatic environment. Environmental International 32, 967-976.

Morrison, R. T., Boyd, R. N., 1992. Organic Chemistry. Prentice-Hall, Inc., New Jersey.

Naseh, M. V., Khodadadi, A. A., Mortazavi, Y., Sahraei, O. A., Pourfayaz, F., Sedghi, S. M., 2009. Functionalisation of carbon nanotubes using nitric acid oxidation and DBD plasma. World Academy of Science, Engineering and Technology 49,177-179. 
Newcombe, G., Dixon, D., 2006. Interface science in drinking water treatment: theory and applications, volume 10. Academic Press, London.

Noh, J. S., Schwarz., 1988. Estimation of the point of zero charge of simple oxides by mass titration. Journal of Colloid and Interface Science 130(1), 157-164.

Noh, J. S., Schwarz., 1990. Effect of $\mathrm{HNO}_{3}$ treatment on the surface acidity of activated carbon. Carbon 28(5), 675-682.

Nozaic, D. J., Freese, S. D., Thompson, P., 2001. Longterm experience in the use of polymeric coagulants at Umgeni water. Water Science and Technology 1(1), 45-50.

Osorio, A. G., Silveira, I. C. L., Bueno, V. L., Bergmann, C. P., 2008. $\mathrm{H}_{2} \mathrm{SO}_{4} / \mathrm{HNO}_{3} / \mathrm{HCl}$ functionalization and its effect on dispersion of carbon nanotubes in aqueous media. Applied Surface Science 255, 2485-2489.

Pei, X., Hua, L., Liu, W., Hao, J., 2008. Synthesis of water-soluble carbon nanotubes via surface initiated redox polymerization and their tribological properties as water-based lubricant additive. European Polymer Journal 44, 2458-2464.

Pereira, M.F.R., Soares, S.F., Orfao, J.J.M., Figueiredo, J.L.,2003. Adsorption of dyes on activated carbons: influence of surface chemical groups. Carbon 41, 811-821.

Potgieter-Vermaak, S., Maledi, N., Wagner, N., van Heerden, J. H. P., van Grieken, R., Potgieter, J. H., 2011. Raman spectroscopy for the analysis of coal: a review. Journal of Raman Spectroscopy 42, 123-129. 
Ramesh, B. P., Blau, W. J., Tyagi, P. K., Misra, D. S., Ali, N., Gracio, J., Cabral, G., Titus, E., 2006. Thermogravimetric analysis of cobalt-filled carbon nanotubes deposited by chemical vapour deposition. Thin Solid Films 494, 128-132.

Rengaraj, S., Yeon, K.H., Moon, S.H., 2001. Removal of chromium from water and wastewater by ion exchange resins. Journal of Hazardous materials 87, 273-287.

Rodriguez-Santiago, V., Vidojkovic, S., Fedkin, M. V., Lvov, S. N., and Wesolowski, D. J., 2008. Zeta potential of deposit components at elevated temperatures. Available at http:// www.icpws15.de/papers/06_Electro-07_rodriguez-santiago.pdf. Accessed October 2011.

Roussy, J., van Vooren, M., Guibal, E., 2004. Chitosan for the coagulation and flocculation of mineral colloids. Journal of Dispersion Science and Technology 25 (5), 663-677.

Rurlle, B., Peeterbroeck, S., Gouttebaron, R.., Godfroid, T., Monteverde, F., Dauchot, J., Alexandre, M., Hecq, M., Dubois, P., 2007. Functionalization of carbon nanotubes by atomic nitrogen formed in a microwave plasma $\mathrm{Ar}+\mathrm{N} 2$ and subsequent poly grafting," Journal of Materials Chemistry 17, 157-159.

Sadr, G. S. B., Beatson, P. J., Schneider, R. P., Fane, A. G., 1998. Water reclamation from municipal wastewater using combined microfiltration-reverse osmosis (MF-RO): Preliminary performance data and microbiological aspects of system operation. Desalination, 116, 65-80.

Sahachaiyunta, P., Koo, T., Sheikholeslami, R., 2002. Effect of several inorganic species on silica fouling in RO membranes. Desalination 144, 373-378. 
Saito, R., Dresselhaus, G., Dresselhaus, M. S., 2000. Trigonal warping effect of carbon nanotubes. Physical Review B 61(4), 2981-2990.

Savage, N., Diallo, M. S., 2005. Nanomaterials and water purification: Opportunities and challenges. Journal of Nanoparticle Research 7, 331-342.

Seo, G. T., Suzuki, Y., Ohgaki, S., 1996. Biological powdered activated carbon (BPAC) microfiltration for wastewater reclamation and reuse. Desalination 106, 39-45.

Simate, G. S., Iyuke, S.E., Ndlovu, S., Yah, C., Walubita, L. F., 2010. The Production of Carbon Nanotubes from Carbon Dioxide: Challenges and Opportunities. Journal of Natural Gas Chemistry 19(5), 453-460.

Simate, G. S., Cluett, J., Iyuke, S. E., Musapatika, E. T., Ndlovu, S., Walubita, L. F., Alvarez, A. E., 2011. The treatment of brewery wastewater for reuse: state of the art. Desalination 273, 235-247.

Simate, G. S., Iyuke, S. E., Ndlovu, S., Heydenrych, M., Walubita, L. F., 2012. Human health effects of residual carbon nanotubes and traditional water treatment chemicals in drinking water. Environment International 39(1), 38-49.

Smart, S.K.., Cassady, A. I., Lu, G. Q., Martin, D.J., 2006. The biocompatibility of carbon nanotubes. Carbon 44, 1034-1047. 
Su, F., Lu, C., 2007. Adsorption kinetics, thermodynamics, and desorption of natural dissolved organic matter by multi walled carbon nanotubes. Journal of Environmental Science and Health Part A 42, 1543-1552.

Suzuki, M., Chihara, K., 1988. Heterogeneous coagulation of organic colloid and powdered activated carbon. Water Research 22 (5), 627-633.

Tripathy, T., Ranjan De, B., 2006. Flocculation: A new way to treat the waste water. Journal of Physical Sciences 10, 93-127.

Tsujirnoto, W., Kimura, H., Izu, T., Irie, T., 1998. Membrane filtration and pre-treatment by GAC. Desalination 119, 323-326.

Upadhyayula, V. K. K., Deng, S., Mitchell, M. C., Smith, G. B., 2009. Application of carbon nanotube technology for removal of contaminants in drinking water: a review. Science of the Total Environment 408, 1-13.

Weber, W. J., LeBoeuf, E. J., 1999. Processes for advanced treatment of water. Water Science and Technology 40(4-5), 11-19.

Wiesner, M. R., Lowry, G. V., Alvarez, P., Dionysiou, D., Biswas, P., 2006. Assessing the risks of manufactured nanomaterials. Environmental Science and Technology 40(14), 4336-4337.

Wu, C. H., 2007. Adsorption of reactive dye onto carbon nanotubes: Equilibrium, kinetics and thermodynamics. Journal of Hazardous Materials 144, 93-100. 
Xu, X. J., Huang, S. M., 2007. Carbon dioxide as a carbon source for synthesis of carbon nanotubes by chemical vapour deposition. Materials Letters 61, 4235-4237.

Xu, T., Yang, J. Liu, J., Fu, Q., 2007. Surface modification of multi-walled carbon nanotubes by $\mathrm{O}_{2}$ plasma. Applied Surface Science 253, 8945-8951.

Yah, C. S., Iyuke, S. E., Simate, G. S., Unuabonah, E. I., Bathgate, G., Matthews, G.; Cluett, J. D., 2011. Continuous Synthesis of Multi-walled Carbon Nanotubes from Xylene Using the Swirled Floating Catalyst Chemical Vapour Deposition Technique. Journal of Materials Research 26 (5), 640-644.

Zhang, N, Xie, J., Varadan, V. K., 2002. Functionalisation of carbon nanotubes by potassium permanganate assisted with phase transfer catalyst. Smart Materials and Structures 11, 962-965.

Zhang, L., Ni, Q-Q., Fu, Y., Natsuki, T., 2009. One-step preparation of water-soluble single-walled carbon nanotubes. Applied Surface Science 255, 7095-7099.

Zhou, Y., Franks, G. V., 2006. Flocculation mechanism induced by cationic polymers investigated by light scattering. Langmuir 22, 6775-6786.

Zouboulis, A.I., Matis, K.A., 1995. Removal of cadmium from dilute solutions by flotation. Water Science Technology 31(4-5), 315-326. 